\title{
Representaciones de estudiantes de primaria y secundaria sobre las Ciencias de la Computación y su oficio.
}

\section{Primary and Secondary School Students' Representation about Computer Sciences and their Job.}

\author{
María Cecilia Martinez \\ CONICET- Universidad Nacional de Córdoba. Argentina \\ cecimart@gmail.com \\ María Emilia Echeveste \\ CONICET- Universidad Nacional de Córdoba. Argentina \\ meecheveste@gmail.com
}

\begin{abstract}
Resumen
Este artículo estudia la oferta de enseñanza en computación en 19 escuelas primarias y secundarias, públicas y privadas de la Provincia de Córdoba, Argentina. Posterior al desarrollo de un curso de introducción a la programación de 13 horas de duración a través de la creación de animaciones, analizamos los principales factores relacionados a la elección de las carreras en computación: representaciones de los estudiantes respecto al oficio de un especialista en computación, representaciones sobre la disciplina, y autopercepción de competencia. Usamos como herramientas principales de recolección de datos pre y post encuestas. Nuestros datos indican que la gran mayoría de las escuelas enseñan a sus alumnos a "usar" la computadora y software elaborados por otros y una menor cantidad de escuelas enseñan competencias relativas al pensamiento computacional y a la programación. Si bien la brecha se profundiza entre las escuelas privadas y públicas, observamos que todos los estudiantes cambian sus representaciones sobre el oficio y la disciplina a partir de nuestro curso introductorio. No cambian la cantidad de alumnos que tenían percepciones positivas o negativas después de la experiencia. Pero sí cambian las razones por las cuales perciben que pueden o no programar. Desarrollamos implicancias para las políticas públicas.
\end{abstract}

\section{Palabras Claves}

Representaciones de los jóvenes, codificación, programación, ciencias de la computación.

\begin{abstract}
This paper studies approaches to introduce computer sciences in 19 primary, secondary, public and private schools in Córdoba Province, Argentina. After offering a 13 hours introductory programming course through the development of computer animations, we analyse the main factors related to Computer Science career choice: students' representations about Computer Scientist job's demand, students' beliefs about the disciplinary area of Computer Science, and students' self-perception of competence using pre and post course survey. Our data show that most schools are teaching their students to "use" the computer and software developed by others, and fewer schools are teaching computational thinking and programming. The computer content knowledge teaching gap is wider when comparing private and public schools. However, after our 13 hours course all of the students changed their representations about Computer Science and its jobs. The amount of students who had positive or negative perceptions do not change after our teaching experience. Nevertheless, the reasons why they perceived themselves as capable or incapable of programming do change. We describe policy implications of these findings.
\end{abstract}

Key words

Youths' representations, codification, programming, computer science. 


\section{Introducción}

En los últimos cinco años se ha profundizado mundialmente la promoción de la enseñanza de las Ciencias de la Computación (CC), y más específicamente el área de Programación en la escuela obligatoria. Muchos países ya han incorporado las CC a su currículo básico tales como Costa Rica, Vietnam, India, Estonia, Australia y más recientemente el Reino Unido (Furber, 2012) y Nueva Zelanda (Bell, 2014).

La demanda por enseñar CC proviene de diferentes sectores que participan de la política educativa. Por un lado, desde el ámbito del desarrollo social se identifica la necesidad de cerrar la Brecha Digital entre distintos sectores sociales (Camacho, 2005). Múltiples estudios apuntan a que los adultos, jóvenes y niños acceden a diferentes tipos de tecnologías y su manejo según la clase social a la que pertenecen (Morales, 2005), poniéndose en tela de juicio la categoría de Nativo Digital (ECDL Foundation, 2015). Asimismo, Benitez Larghi (2013) por ejemplo, señala tres niveles de brecha digital: la brecha de primer orden -acceso a dispositivos tecnológicos-, brecha de segundo orden formación del usuario- y brecha de tercer orden -comprensión y producción de la tecnología-. El autor y sus colegas apuntan a que las brechas de segundo y tercer orden serían las más profundas donde la escuela puede hacer una contribución para un desarrollo social más equitativo.

Desde el sector educativo se exige la alfabetización digital de la ciudadanía en "la técnica cultural de nuestro tiempo" que incluye los lenguajes de computación y la producción digital. Así como durante el desarrollo de los Estados Nación se incorporaron la enseñanza de las letras y las matemáticas a la escuela obligatoria, en la sociedad de la información y la comunicación deberíamos incluir la enseñanza de la programación (Busaniche, 2006). Desde este lugar se enfatiza el rol de la escuela como la encargada de alfabetizar a la ciudadanía en saberes socialmente válidos para que puedan comprender y ser miembros activos del mundo que nos rodea -que es en gran parte digital-. La alfabetización en los lenguajes de nuestro tiempo es vista como un derecho educativo a cargo de la escuela y donde los Estados Nación son garantes de ese derecho.

Desde la ciencia y la industria, la gran demanda del desarrollo científicotecnológico de los países y la escasez de trabajadores formados en estas áreas, han sido los motivos por los cuales se impulsa la enseñanza de la CC en la escuela. Por un lado la industria tecnológica se ha expandido considerablemente en la última década. Por ejemplo en Argentina, nuestro país, la industria del Software ha crecido un $370 \%$ en el último decenio (Fundación Sadosky, 2013). Sin embargo, la matrícula y el nivel de egresados en carreras de computación se mantienen o disminuye. Para el caso de Argentina se calcula que la industria y la ciencia requieren anualmente de 7500 egresados de carreras de computación siendo que el número de profesionales que terminan carreras del sector es alrededor de 3000. Es decir, la demanda es el doble de la oferta.

Para fortalecer la cantidad y calidad de egresados de carreras relacionadas con la computación, el gobierno argentino ofrece una serie de becas e incentivos ${ }^{1}$ destinadas a los estudiantes universitarios. Sin embargo, a pesar de los incentivos, los estudiantes no

1 Ver por ejemplo: Becas 1000 x 1000 y 1000 x 1500, Becas Progres.ar, Becas Bicentenario, Becas TIC de Finalización; Becas de la Universidad Nacional de Córdoba (UNC), como ser PIOE y Becas de Ingresantes. 
seleccionan estas carreras para seguir sus estudios universitarios. Diferentes autores apuntan a que hay tres factores claves en la selección de carreras relacionadas con la computación: 1) acceso temprano a la disciplina, 2) autopercepción de competencia 3) representaciones sobre el oficio y sobre la disciplina (Manaris, 2007; Scott, Fuller, MacIndoe y Joshi, 2009). Por acceso temprano se entiende un acercamiento a la disciplina ciencias de la computación y uso de computadoras desde una pronta edad. La autopercepción de competencia refiere a las habilidades percibidas sobre sí mismo para dedicarse a una carrera de computación y representaciones sobre el oficio son las ideas, miradas, visiones y conocimientos sobre lo que constituye la disciplina y el trabajo en el área. Estos factores estarían relacionados con las experiencias de enseñanza que los niños y jóvenes han tenido en su escuela. Es por ello que quisimos saber cómo responde la escuela a las múltiples demandas desde el desarrollo social, educativo y científico tecnológico de un país en un contexto donde hay un vaciamiento curricular sobre el tema e indagar si hay diferencias en la oferta de enseñanza de computación según los diferentes tipos de escuelas -orientaciones curriculares y tipo de gestión-.

Sostenemos que la escuela obligatoria -primaria y secundaria- tiene un rol fundamental en la alfabetización de los saberes básicos, el achicamiento de las brechas sociales, y las representaciones que los jóvenes construyen sobre las diferentes disciplinas. Nos preguntamos entonces cómo el modo en que se enseña CC contribuye a un tipo de representaciones sobre el oficio, la disciplina y la auto competencia percibida.

Este artículo analiza la oferta de enseñanza en el área de computación en 19 escuelas primarias y secundarias, públicas y privadas de la Provincia de Córdoba. A partir de una intervención educativa con una experiencia de enseñanza de programación en computación. Luego, analiza cuáles eran las representaciones sobre la disciplina que tenían los alumnos antes y después de la intervención en cada una de las escuelas.

Los objetivos de esta investigación son entender cuál es la oferta de enseñanza de CC en escuelas primarias y secundarias, públicas y privadas de la Provincia de Córdoba, Argentina y analizar la relación entre las experiencias de aprendizaje de CC que se ofrecen y las representaciones, acceso a la disciplina y percepción de competencia que construyen los alumnos.

El valor de esta investigación radica fundamentalmente en documentar el tipo de saberes sobre computación que se transmiten en la escuela actualmente y cómo esos saberes van configurando un modo de ver la disciplina en cuestión. Encontramos específicamente que una mayor proporción de escuelas de gestión privadas tienen una oferta de enseñanza ligada a la programación en computación que difiere a la formación del usuario como operadores de software. Un mayor porcentaje de estudiantes de estas escuelas ven a las CC como una disciplina creativa, en donde además de usar la computadora, pueden programarla y crear nuevos productos tecnológicos como videojuegos. Observamos así que la técnica cultural de nuestro tiempo es transmitida en mayor medida por las escuelas privadas que las escuelas públicas teniendo efectos en la mirada que construyen los jóvenes y niños sobre el saber en torno a la computación. La sección que sigue describe aportes teóricos que guiaron la indagación de esta investigación. 


\section{La escuela secundaria y las políticas educativas}

Como investigadoras en Ciencias Sociales consideramos que la educación es y ha sido siempre un componente insoslayable en la construcción social y una coproductora de subjetividades. Profundizando en el sentido y la función de la escuela, nos encontramos con la necesidad de continuar trabajando para el mejoramiento y la inclusión no sólo de los jóvenes en la escuela pública sino de conocimientos que sean verdaderamente democratizadores, rompiendo así las brechas de conocimiento que son invisibilizadas.

Tiramonti (2013) plantea una preocupación actual por la escuela media al considerar dificultades en los jóvenes para construir interés y sentido en su paso por la escuela. Ya no se encuentra la referencia que otorgaba sentido a la escolarización media y las tradicionales articulaciones entre educación, trabajo y ciudadanía, que si bien no han desaparecido, están mediadas por otra serie de recursos, que relativizan el lugar de la educación como formadora de ciudadanía y garante de inserción laboral.

Durante las últimas décadas muchos de los países de la región latinoamericana como Argentina, Uruguay, Perú, Chile, Bolivia, Nicaragua, Guatemala, Brasil y El Salvador, han revisado su legislación y han dictado nuevas leyes en materia de educación en la que explicitan renovadas visiones y soluciones institucionales para las problemáticas educativas nacionales. Estos cambios tienen la intención de redefinir el marco jurídico que se generó fundamentalmente en el neoliberalismo que marcó la década de los 90, donde se consideraba fuertemente a la educación como capital de consumo y privatización, buscando actualmente orientarse en favor de una mayor presencia de la institución estatal como garante. En este marco, los estados introducen recursos y equipamiento que permiten (re) pensar el vínculo entre Educación y TIC (Tiramonti, 2013). Así se piensa mejorar la calidad educativa a partir de contenidos socialmente válidos que permitan la formación de ciudadanos activos e incluidos a partir del conocimiento en la sociedad.

\section{¿Por qué pensar en la enseñanza de las Ciencias de la Computación?}

Durante la década del 2000 se generaron políticas educativas orientadas a estrategias de integración e inclusión de los jóvenes y niños. Este objetivo pretendía, entre otras cosas, proveer de una red institucional que articulara en la sociedad al creciente número de jóvenes que se encontraban en la situación de no estudiar ni trabajar $^{2}$ (los "NI-NI"). Estas políticas de Estado han logrado que muchos sectores que tradicionalmente no iban a la escuela, ahora estén matriculados y asistiendo a centros escolares. El gran desafío pendiente es incluirlos educativamente, con una oferta académica de calidad.

En las últimas décadas los gobiernos proponen una nueva configuración cultural donde la escuela recupera su centralidad como institución social incluyendo nuevas tecnologías en su oferta de enseñanza. No sólo porque actualmente estamos rodeados de

\footnotetext{
2 Algunos ejemplos de ellos son programas de re-inserción educativa para jóvenes entre 14 a 17 años, programas de terminalidad educativa para jóvenes y adultos con el secundario inconcluso mayores de 18 años, programas de oficio con salida laboral, becas, subsidios y seguros sociales para finalizar el secundario o insertarse en el primer empleo, etc.
} 
tecnología cada vez más embebida en nuestra cotidianidad, sino porque la mayoría de los jóvenes conforman su subjetividad alrededor de una disponibilidad tecnológica que crece continuamente. La tecnología es parte de la comunicación y sociabilidad de los jóvenes a través de los teléfonos inteligentes y las redes sociales, y es parte de sus actividades de ocio con el uso de las consolas de video juegos, fotografía digital e Internet, por ejemplo.

Si consideramos a la escuela como una institución socio-histórica debemos comprender su carácter dinámico y su necesidad de cambio, lo cual requiere incorporar las configuraciones culturales que se van aconteciendo. Los modos de producir y transmitir conocimiento requieren transformaciones en los saberes que se distribuyen en la escuela. De esta manera, nos parece oportuno revisar y re pensar el trayecto de las Ciencias de la Computación en el sistema educativo.

\section{La oferta en enseñanza en Informática/Ciencias de la Computación en Argentina}

Antes de comenzar con una revisión histórica quisiéramos clarificar que en la bibliografía específica se advierte una terminología confusa en el área de la Computación donde términos como Informática, Computación, Tecnologías de la Información, entre otras, suelen ser usados como sinónimos. Estas acepciones difieren en sus alcances aunque muchas veces se solapan. Particularmente preferimos usar Ciencias de la Computación, al referir a la disciplina de fundamentos y principios independientes de tecnologías concretas, que incluyen programación, algoritmos, estructuras de datos, arquitecturas y redes de computación, como así también habilidades y competencias mentales que hacen al pensamiento computacional, como la descomposición en subproblemas, generalización y abstracción de casos particulares, modelización y formalización, proceso de diseño, implementación y prueba (Shackelford, 2006).

Una rápida revisión histórica sobre las formas en que se ha introducido la computadora en la escuela permite observar su carácter dinámico y el importantísimo papel que han jugado las políticas educativas en este proceso. Las primeras experiencias de incorporación de la computación en la educación media de Argentina tuvieron lugar a comienzos de la década de 1980, durante la dictadura militar, donde se utilizaba el lenguaje de programación BASIC como herramienta complementaria para comprender conceptos matemáticos.

A partir de 1985 se expandió en la educación el uso del lenguaje de programación LOGO creado por Pappert, quien consideraba que la principal función de las computadoras en la escuela no consistía en aumentar la calidad de los aprendizajes ya habituales, sino en crear nuevas formas de aprender y nuevas condiciones de aprendizaje (Levis y Gutiérrez, 2000). Acompañando la enseñanza del pensamiento computacional se abordaba la formación técnica centrada en el hardware de la computadora donde el objetivo era entender cómo y por qué funcionaban estos nuevos dispositivos. Por ello, Levis (2007) se refiere a que en esta etapa predominaba el paradigma técnico-operativo de la enseñanza de la computación.

Hacia finales de la década del 80 y comienzos de los 90 se incrementa significativamente el equipamiento en los colegios públicos, en especial de enseñanza media, favoreciendo la expansión de software educativo de manera muy desigual entre las provincias. En 1993, se sanciona la Ley Federal de Educación planteando un cambio 
en la incorporación de la computación en las escuelas. En esta década, se lanzó el programa "Más y mejor Educación para todos" donde se pretendía incorporar a las TIC (Tecnologías de la Información y la Comunicación) y a la utilización pedagógica de la informática en la educación. Sin embargo, algunos autores sostienen que este programa no logró cumplir ninguno de sus propósitos (Levis, 2007).

Como bien observamos, la computación ha intentado incorporarse en la escuela con distintas propuestas. Ya en la década de los 90s, el Estado Nacional establece un acuerdo de cooperación con Microsoft e IBM delegándole a los dos monopolios del software estadounidense los recursos informáticos para las escuelas. Estas empresas privadas se encargarían de la formación de los docentes de enseñanza básica y media de todo el país. Esta enseñanza tenía una fuerte concepción operativa e instrumental de la tecnología, reduciéndolo a un aprendizaje utilitario de los programas, desarrollados por una de las empresas, como lo son Word y Excel -llamados ofimática- en detrimento de los conceptos propios de la disciplina Ciencias de la Computación, brindando así la ilusión de estar formando a los jóvenes y niños en esa área. Este modelo prometía la formación laboral en computación que posibilitaría la inserción en cualquier tipo de trabajo. Es por eso que durante esta etapa Levis considera que predomina el paradigma utilitario de la enseñanza de la computación en la escuela (Levis, 2007).

El convenio que firmó el Estado sobre el uso de software privativo de Microsoft es de duración ilimitada pero en 2006 se sanciona una nueva Ley de Educación Nacional (L.E.N. 26.206) donde se replantea la enseñanza de las TIC en dos direcciones. Por un lado, la LEN da lugar a que algunas escuelas secundarias, tengan en los tres últimos años de escolaridad la orientación en informática que requiere de la enseñanza de asignaturas propias del área. La otra dirección propone para el resto de los niveles del sistema educativo obligatorio la "integración" de las TIC en todas las asignaturas que enseña la escuela. Con esta "integración" de las TIC se busca lograr dos objetivos: 1) potenciar los aprendizajes de las distintas materias a partir de los recursos que permite la tecnología -visuales, auditivos, de producción artística, simulaciones, etc.- 2) lograr la alfabetización digital de segundo orden en tanto uso de software y programas disponibles en el mercado. Este enfoque de la enseñanza de la computación en la escuela es denominado "paradigma integrador". Contrariamente al paradigma utilitario sí se incorporan software específicamente educativo, como por ejemplo simuladores.

En este mismo período histórico van ganando lugar las organizaciones de Software Libre, y se desarrolla un nuevo sistema operativo nacional llamado "Huayra". Se le da un nuevo empuje, en términos de aumento de la oferta y de la calidad de los recursos, al portal en línea nacional de educación llamado "Educ.ar" y se crea el proyecto Conectar Igualdad, programa 1 a 1 de la República Argentina que otorga una netbook a todos los estudiantes y docentes de escuelas secundarias públicas. A pesar de que el programa Conectar Igualdad nace con el objetivo de integrar la tecnología a la escuela para potenciar el aprendizaje de contenidos obligatorios del sistema, se discute a partir del 2014 y con gestiones de la Fundación Sadosky -dependiente del Ministerio de Ciencia, Técnica e Innovación Productiva de la Nación- y de Universidades Nacionales, la posibilidad de enseñar programación en las escuelas en cinco foros regionales en todo el país.

La descripción realizada da cuenta de los cambios en la valoración de las Ciencias de la Computación y la tecnología en nuestra educación. Autores como Busaniche (2006) sugieren que las escuelas deberían enseñar lenguajes de programación 
y conceptos centrales de la computación para que los alumnos tengan la posibilidad de producir tecnología en vez de solamente consumirla. Este paradigma es clasificado por Levis como el paradigma "lingüístico-cultural".

\section{Procesos de apropiación de la tecnología. Escuelas públicas y privadas.}

Actualmente contamos con distintos conceptos que intentan explicar la desigualdad y el impacto social de las nuevas tecnologías. Entre los más conocidos se encuentra el término "brecha digital". Camacho (2005) debate sobre este término y plantea la necesidad de pensarlo complejamente sin caer en la simplicidad de acceso, equipamiento y conexión física, lo que Camacho denominó brecha de primer orden. Más allá de la brecha del acceso se advierte una segunda brecha relativa al uso de las TIC diferenciado que realizan los distintos actores según sus posiciones en el campo social en tanto cantidad y calidad de capitales culturales y educativos (Bourdieu, 1991). La brecha de tercer orden, en tanto, nos remite a una apropiación de las tecnologías para la producción y el desarrollo de nuevos productos tecnológicos.

Las nuevas tecnologías de información y comunicación no son neutrales a las desigualdades de clase. Distintas investigaciones señalan que los jóvenes de clases populares tienen un primer contacto tardío con la computadora e internet, realizando muchas veces estas actividades en espacios de acceso públicos como ser las escuelas o los cyber-cafés (Urresti, 2008; Benítez Larghi, 2010). Sin embargo, este panorama cambió con la implementación del Programa Conectar Igualdad a partir de 2010, permitiendo cerrar la brecha de primer orden, proporcionando una computadora a cada alumno.

La investigación realizada por el equipo de Benitez Larghi (2013), muestra que los jóvenes de clases medias altas se apropian de las TIC en contextos de abundancia tecnológica, en donde la mayoría tiene otras computadoras en sus hogares aparte de la entregada por el Estado. Las trayectorias de acercamiento a las TIC son heterogéneas y en ellas intervienen distintos factores: sociales, generacionales, económicos, de género y culturales, entre otros. Los actuales jóvenes de sectores medios y altos nacieron en hogares provistos de tecnología y conectividad; donde sus padres ya fueron usuarios de la computadora e Internet, y donde suelen contar desde edades tempranas con computadoras personales.

Esta diferencia también suele perpetuarse al considerar a los jóvenes de clases altas como usuarios más intensos quienes desarrollarían habilidades diferentes a las de jóvenes de clases populares (Bouille, 2008). Sin embargo esta condición sólo refleja las ventajas de clases en relación al uso y acceso de la computadora pero no aborda la brecha de tercer orden en tanto uso intensivo de la tecnología para producir más y mejor tecnología.

Si volvemos a retomar la participación del Estado en la inclusión educativa debemos reconocer que se ha generado un gran avance en políticas educativas, sin embargo, actualmente se continúa observando la reproducción de capitales "heredados". Bourdieu (1991) compara al funcionamiento del sistema escolar con una ley termodinámica a la cual llama: Demonio de Maxwell, operación de selección que mantiene el orden preexistente, separando a los alumnos dotados de cantidades desiguales de capital cultural. Esto se ve reforzado con lo que plantea Ortega (2008) cuando menciona que los espacios educativos, son lugares donde se evidencian las 
desigualdades sociales, se construyen subjetividades y se ponen en juego las trayectorias particulares de los estudiantes. Para estos autores, a pesar de las políticas de estado, se mantienen las diferencias existentes entre las escuelas privadas y las escuelas públicas en relación al acceso a determinados conocimiento. Mónica Maldonado (2000) expresa que en el contexto de Córdoba, Argentina:

"las escuelas públicas son visualizadas como escuelas para pobres, "de segunda", mientras que las privadas parecen dar cuenta de "gente pudiente", con poder, y como tales están organizadas de modo de ofrecer servicios actualizados "de primera" (Maldonado, 2000. p: 15).

Es necesario visibilizar estas diferencias para poder repensar propuestas educativas relacionadas al acceso del saber socialmente válido y a la nueva técnica cultural que contribuyan a cerrar brechas de conocimiento. Bourdieu (1979) considera la posibilidad de cambio y menciona que a un volumen de capital heredado corresponde un haz de trayectorias más o menos equiprobables que conducen a unas posiciones más o menos equivalentes. Y el paso de una trayectoria a otra depende a menudo de acontecimientos colectivos (guerras, crisis, etc.) o individuales (ocasiones, amistades, protecciones, etc.) que comúnmente son descritos como casualidades. En este sentido, pensamos que las ofertas educativas de la escuela pueden potenciar o promover estos acontecimientos que orientan la trayectoria educativa de los jóvenes. De esta manera creemos en la necesidad de poner en tensión la enseñanza de las Ciencias de la Computación y analizar el modo en que se accede a este conocimiento.

\section{Percepciones de los jóvenes sobre la disciplina.}

Según investigaciones realizadas en Iberoamérica en cuanto a la percepción de los jóvenes sobre las ciencias y la profesión científica (Organización de los Estados Iberoamericanos, OEI, 2009), los principales motivos que explican el desinterés de los jóvenes en la ciencia están relacionados al ámbito educativo y en menor medida al mercado laboral. La mayoría de los estudiantes considera a las materias científicas de las escuelas como aburridas y difíciles. Sin embargo 7 de cada 10 estudiantes piensa que los contenidos de las clases de ciencia se pueden entender si están bien explicados.

Sin caer necesariamente en culpabilizar a actores sociales, el contexto educativo presenta un papel importante en la concepción que los jóvenes realizan sobre las disciplinas y sus asignaturas, lo que contribuye a conformar representaciones de las respectivas profesiones y oficios. Un punto fuerte que mencionan los alumnos en las investigaciones realizadas por la OEI y el Observatorio de la Ciencia, la Tecnología y la Innovación, tiene que ver con el modo en que los profesores enseñan sus asignaturas.

Según el informe de PISA de 2006 hay una distancia entre la disposición que tienen los alumnos para aprender y valorar el conocimiento científico y sus motivaciones para que la ciencia forme parte de su futuro profesional y personal. A modo de hipótesis, el estudio sugiere que una de las razones por lo que la mayoría de los jóvenes no elige continuar estudiando carreras científicas y tecnológicas tiene relación con desconocer certeramente cuál es el oficio de estas profesiones. Para el caso de las carreras relacionadas con las tecnologías, esto puede observase en el hecho de que si bien todos los jóvenes cuentan con aparatos tecnológicos a su alcance, no logran salirse del mero rol de usuarios. Del mismo modo, muchos jóvenes no logran reconocer referentes ni personalidades locales que representen el oficio de la programación. Las 
investigaciones reflejaron que la mayoría de los jóvenes no reconoce ninguna institución científica argentina u de otros países, ni tampoco identifican a investigadores ni argentinos o extranjeros (OEI, 2009). Esto nos permite repensar sobre la articulación entre el sistema científico y tecnológico con las distintas esferas sociales y productivas.

Los estudios de la OEI arrojaron que un $40 \%$ de estudiantes consideraban que un científico es alguien distinto, con una inteligencia superior, y plantearon que la mayoría de los jóvenes finalmente no contempla la posibilidad de dedicarse a la investigación científica a la hora de imaginarse su futuro profesional. Sin embargo, se observa un aumento en la proporción de adolescentes que se interesan por la práctica científica cuando considerar aspectos que involucran tareas propias de esta actividad. Muchos reportan no interesarles las actividades científicas pero les gustan actividades que involucren descubrir cosas nuevas o ayudar a encontrar soluciones. Ello podría ser indicativo de una posible distancia y abstracción conceptual que encuentran en el término "investigación científica", como también en el desconocimiento del qué hacer científico.

Informes internacionales como "Shut down or restart?" (Furber, 2012) y "Running on Empty" (Association for Computer Machinery and Computer Science Teachers Association, 2010) indican que los contenidos que las escuelas enseñan actualmente sobre computación no sólo contribuyen muy poco a la formación de los alumnos, sino que en muchos casos resulta contraproducente en relación con los objetivos de desarrollar intereses por las carreras del área. Incluso, no logran aportar a la apropiación de conocimientos y habilidades fundamentales para las demandas actuales. Esto tienen gran influencia en las representaciones que los jóvenes se hacen de la disciplina y de su oficio, por ello es que nos vamos a detener en pensar de dónde vienen nuestras representaciones y cómo predisponen nuestra mirada.

\section{¿De dónde surgen éstas representaciones? Reflexiones desde el campo social.}

Las representación que nos hacemos sobre las distintas disciplinas no están aisladas, no surgen ex nihilo. Somos individuos socializados y formamos parte de un campo socio-histórico donde tienen una fuerte presencia las instituciones y las significaciones que hacemos de la sociedad. Castoriadis (1997) plantea la noción de significaciones imaginarias sociales, las cuales definen de modo absolutamente arbitrario las representaciones, los deseos y los actos de los sujetos. De esta manera, nuestra forma de pensar sobre determinadas áreas tampoco es libre de alteridad y responden tanto a otros como a pensamientos colectivos, la mayoría de las veces sin ser controlados conscientemente.

"El pensamiento es esencialmente histórico, cada manifestación del pensamiento es un momento en un encadenamiento histórico y es también -si bien no exclusivamente - su expresión. De la misma manera, el pensamiento es esencialmente social, cada una de sus manifestaciones es un momento del medio social; procede, actúa sobre él, lo expresa, sin ser reducible a ese hecho (...) Esta condición no es de ninguna manera "exterior", no pertenece a la infinidad de condiciones necesarias pero no suficientes que subyacen a la existencia de la humanidad. Es una condición "intrínseca", una condición que participa activamente de la existencia de aquello que condiciona." (Castoriadis, C 1997; p3)

De esta manera estamos obligados a considerar lo histórico y social como condición 
esencial de la existencia del pensamiento y la reflexión. Según Castoriadis, sociedad e historia son, principalmente, fenómenos de sentido.

Estamos atravesando como sociedad un momento de cambio asimilado a distintas revoluciones históricas como lo fueron la Escritura, la Invención de la Imprenta y la Revolución Industrial, denominado Revolución Tecnológica. Las personas que dominen las tecnologías tendrán una enorme ventaja sobre el resto y podrán potenciar sus capacidades productivas y posibilidades de ponerlas al servicio de temas esenciales como la salud, la seguridad, la educación. Aquellos que no dominen la tecnología tendrán un nivel importante de dependencia (Fundación Sadosky, 2013).

Las representaciones sociales, se construyen en la comunicación social, se ocupan de indagar creencias específicas que se encuentran en el saber cotidiano socialmente instituido. La elaboración de las representaciones sociales moviliza componentes del posicionamiento ante el mundo y nos proporcionan un marco para interpretar los fenómenos que nos rodean, incluso condicionan la percepción y las vivencias respecto de uno mismo (Castorina y Barreiro, 2006).

Las prácticas sociales y la educación contribuyen a romper con el desconocimiento que legitima las desigualdades, permitiéndonos desnaturalizar los efectos conservadores que determinan categorías mentales utilizadas para mirar y construir el mundo social y los dispositivos institucionales y pedagógicos de la escuela (Tenti Fanfani, 2007).

La descripción del contexto histórico y el análisis sobre las brechas digitales en nuestra sociedad, los conceptos trabajados sobre los paradigmas de introducción de la computación en la escuela, la construcción de representaciones que hacen los jóvenes sobre el trabajo científico y su relación con la enseñanza de la ciencias; constituyen aproximaciones teóricas fundamentales para orientar nuestra indagación en este estudio. A continuación explicamos el diseño del mismo.

\section{Métodos e intervención}

Esta investigación es parte de un programa piloto de enseñanza de las CC que aborda tres ejes: formación docente, desarrollo de materiales didácticos y diseño y piloteo de experiencias de enseñanza de las CC en escuelas primarias y secundarias. Este programa es coordinado por un equipo interdisciplinario llamado UNC++ de la Universidad Nacional de Córdoba integrado por docentes de Computación, Educación, Psicología y Trabajo Social ${ }^{3}$.

Durante 2014 el programa ofreció un curso de capacitación docente en la enseñanza de la programación en computación en el cual participaron 38 docentes de 19 escuelas. Uno de los requisitos del curso, era participar con un par docente de la misma escuela para promover el apoyo de la puesta en práctica de la innovación. Los docentes se reunieron con una frecuencia mensual de 4 horas por encuentro para aprender conceptos introductorios de la programación y su didáctica. Los docentes se inscribieron al curso por interés propio -autoseleccionados- y pertenecían a escuelas públicas y privadas, primarias y secundarias de la Provincia de Córdoba, Argentina. Una experiencia piloto de este curso se realizó durante $2013^{4}$.

3 Página web del equipo: http://masmas.unc.edu.ar/

En esa ocasión encontramos que el formato del formación docente planteado en "comunidades

Representaciones de estudiantes de primaria y secundaria sobre las Ciencias de la Computación y su oficio. M. Cecilia Martínez y M. Emilia Echeveste.

Página 10 de 38 
Nuestro curso de capacitación a docentes ofreció además planes de clase elaborados desde la perspectiva del aprendizaje por descubrimiento -disponibles en nuestra página de web- para enseñar programación a partir del desarrollo de animaciones y videojuegos con la plataforma de acceso libre Alice ${ }^{5}$. Con ayuda de un tutor de la universidad que visitaba cada una de las escuelas durante una jornada, y con el aporte que ofrecía el seguimiento mensual del curso y el par docente de la escuela; los docentes pusieron en práctica estos planes de clase -previamente piloteados durante 2013- con sus propios alumnos por un total aproximado de 13 horas distribuidas a lo largo de un cuatrimestre.

El curso de programación de 13 horas abordaba alguno de los principales conceptos de la programación: iteraciones, objetos, códigos, parámetros, ciclos, condicionales, variables, secuencia, atributos, y métodos. Como así también competencias propias de la disciplina tales como comentar el código, explorar una plataforma, trabajo en grupo, etc. El objetivo central del curso introductorio era mostrar que la programación en computación es una habilidad accesible a todos, que todos los niños y jóvenes pueden aprenderla, que es innatamente creativa, y que muchos de estos conceptos se aplican a plataformas de uso cotidiano como el Smart TV, la tostadora, la alarma, etc.

Los planes de clases sugieren cuatro momentos principales para enseñar programación en la escuela:

1) Motivación y Recuperación de ideas previas: momento orientado a desafiar y generar interés en los alumnos por utilizar un concepto nuevo de ciencias de la computación recuperando conocimientos previos.

2) Demostración y análisis: breve introducción al concepto que puede resolver el desafío planteado. Intencionalmente el docente no resuelve todo el desafío, dejando lugar para la exploración y el descubrimiento de diferentes instancias de aplicación del concepto.

3) Exploración y Producción: los estudiantes exploran la plataforma buscando las herramientas que, combinadas con el concepto nuevo, puedan resolver el desafío. Esta es una competencia importante ligada al modo en que trabajan los especialistas en Ciencias de la Computación.

4) Reflexión: durante el último segmento de la clase, los alumnos comparten sus producciones, reflexionan y analizan sus avances apoyándose en una grilla que les permite hacer foco en "cómo les está yendo" y "qué necesitan hacer para mejorar".

Nuestros materiales están orientados a desarrollar competencias de alto orden y específicas de las CC tales como análisis de un problema social o tecnológico, partición de ese problema en sub problemas, y análisis del proceso y autoevaluación, considerados claves en la formación en computación (Wing, 2006).

Además, los jóvenes, niños y niñas de las escuelas participantes asistieron antes de tomar las clases de computación en sus escuelas, a una jornada "motivadora" en la

de aprendizaje", lograba cambiar las creencias de los docentes sobre la enseñanza de la computación (Martinez y Echeveste, 2014).

5 Alice es una plataforma didáctica para enseñar conceptos centrales de la programación en Computación desarrollada por la Universidad de Carnegie Mellon. 
Universidad durante la cual profesionales de computación y la medicina describieron cómo la computación contribuía a mejorar su trabajo -usos en cirugías y diagnósticos, en videojuegos, animaciones, productos vestibles para deportistas, y aplicaciones de Google Glass-. Intencionalmente, uno de nuestros oradores era una mujer que trabaja para una empresa internacional de computación. Incorporando a la mujer como panelista pretendimos contribuir a abordar la brecha de género presente en estas carreras (Zuckerfeld, Botta, Dughera, Yansen, 2014). El objetivo de esta jornada era mostrar el oficio y la contribución de la computación a diferentes áreas. Al final del cuatrimestre, los alumnos volvieron a la universidad a mostrar las animaciones y videojuegos que habían realizado en sus escuelas. Para muchos de éstos jóvenes esta experiencia fue su primer contacto con la Universidad pública.

En otros artículos de nuestro equipo hemos analizado cómo este curso aumentó el interés y la motivación por aprender computación (Benotti, Martinez, Schapachnik, 2014) y cómo permitió que los alumnos se apropiaran de conceptos centrales de la programación (Martinez, Gomez, Benotti, 2015). En esta oportunidad nos centramos en analizar la relación entre la oferta de enseñanza de computación en las diferentes escuelas y las representaciones sobre el oficio, la disciplina y autopercepción de competencias que construyen los alumnos.

Si bien la enseñanza de la computación en la escuela ha sido estudiada, sobre todo a nivel universitario, desconocemos cuáles son las representaciones sobre la disciplina que los niños y jóvenes construyen y su relación con la oferta de enseñanza. Parte del objetivo del estudio era identificar cuáles eran estas representaciones a través de analizar los relatos de los jóvenes y niños y construir a partir de ellos categorías analíticas.

Creswell (2013) diferencia entre estudios exploratorios y confirmatorios. Los estudios exploratorios buscan construir categorías a partir de recurrencias en vez de corroborar en diferentes contextos categorías previamente construidas. Para abordar las representaciones realizamos preguntas abiertas a los alumnos que nos permitieran estudiar los discursos de los jóvenes y niños desde los cuales construir una categorización de las representaciones. Estas preguntas fueron repetidas antes y después de la intervención para identificar cambios en las representaciones. Por las características descriptas de la experiencia, el tipo de estudio es exploratorio en tanto estudia un fenómeno nuevo -la enseñanza de la computación en la escuela y las representaciones que construyen los alumnos sobre la disciplina- del cual hay pocos antecedentes de investigación que permitan establecer hipótesis, categorías analíticas o teorías explicativas con el propósito de ganar en la comprensión del fenómeno y contribuir a sentar las bases teóricas, e identificar variables que permitan orientar futuros estudios (Cuthill, 2002). Tanto los nombres de las escuelas como de los alumnos son confidenciales.

\section{Muestra}

En total participaron 19 escuelas y un total de 667 alumnos contestaron las encuestas antes de la intervención piloto (pre encuesta). De estas escuelas, 4 eran de Primaria y 15 de Secundaria. 5 escuelas pertenecen a la gestión privada y 14 a la gestión pública. La tabla 1 resume el perfil de las escuelas. 
Tabla 1: Cantidad de Escuelas por Nivel Educativo y tipo de Gestión

\begin{tabular}{|l|l|l|}
\hline Nivel & Pública & Privada \\
\hline Primaria & 3 & 1 \\
\hline Secundaria & 11 & 4 \\
\hline
\end{tabular}

Al menos la mitad de las escuelas públicas contienen alumnos de sectores empobrecidos que reciben la Asignación Universal por $\mathrm{Hijo}^{6}$ en un $30 \%$ a un $50 \%$ de todo el estudiantado.

Si bien todas las escuelas que completaron la pre encuesta terminaron nuestro programa, solamente 10 escuelas nos enviaron sus post encuestas. En total 263 alumnos de 10 escuelas completaron ambos cuestionarios, pre y post encuestas. De estas 10 escuelas, 4 eran escuelas de gestión privada y 6 pública; y 3 eran de nivel primario y 7 de secundario.

Del total de las escuelas secundarias, 5 tenían para su ciclo de especialización la orientación en informática. Es decir, en los tres últimos años de la secundaria los alumnos deben recibir contenidos de CC según el diseño curricular de esta orientación. Además otras 2 escuelas secundarias eran de orientación Técnica Industrial mientras que el resto de las escuelas secundarias tenían orientaciones no relacionadas con la computación tales como Ciencias Sociales o Ciencias Naturales.

Como nuestro objetivo era describir qué contenidos de computación se ofrecen en las escuelas, qué representaciones sobre la disciplina construyen los alumnos y qué relación puede establecerse entre contenidos enseñados y representaciones; para este artículo tomamos como insumo las pre encuestas de la muestra inicial $(\mathrm{N}=667)$ para describir oferta educativa y luego las pre y post encuestas $(\mathrm{N}=263)$ para describir relación con las representaciones. No hemos analizado aquí el aprendizaje y la puesta en práctica que hicieron los docentes puesto que este artículo presenta un recorte de nuestro programa de investigación. Sin dudas, el análisis del rol docente es una cuenta pendiente.

Herramientas de recolección de datos y análisis

6 La Asignación Universal por Hijo (AUH) es un seguro social que el Estado Argentino otorga a las familias cuyos ingresos están por debajo del salario mínimo. 
Encuestas pre y post intervención fueron la principal herramienta de recolección de datos. Las encuestas fueron elaboradas a partir de una revisión de la bibliografía que aborda las principales dimensiones para analizar los usos y representaciones de los jóvenes sobre las TIC y las CC. Las encuestas abordan las siguientes variables: situación socioeconómica, nivel educativo, usos de la computación en la vida cotidiana, concepciones acerca de la programación, percepción de auto competencia, interés en el área, y perspectiva de elección de carrera. En el Anexo 1 de este artículo se comparte una tabla con las variables de la encuesta y los indicadores utilizados. La encuesta incluye ítems de respuestas abiertas e ítems de múltiple opción.

Como la mayoría de los datos de los alumnos fueron recolectados con preguntas cerradas, de múltiple opción, o de respuestas breves, se trabajó en planillas de cálculos donde cada columna guardaba las respuestas de los alumnos y cada fila el nombre del participante. Se crearon tablas de frecuencia para cada una de las variables. Como el objetivo era poder describir qué contenidos de computación son enseñados en las escuelas y cuáles son las representación que construyen los alumnos sobre la computación y su oficio, tomamos como base el enfoque exploratorio y realizamos para este artículo categorías de manera inductiva a partir de analizar las respuestas de cada uno de los alumnos a las preguntas abiertas. Estas categorías emergentes luego se cruzaron con variables demográficas tales como nivel educativo, tipo de gestión y orientación de la escuela.

En el apartado que continúa describiremos los hallazgos en tres sub secciones diferentes: 1) hallazgos en torno a la oferta de enseñanza de la computación en las escuelas participantes, 2) hallazgos relacionados a las representaciones que los alumnos tienen sobre las CC y la programación y 3) reflexiones en torno a la auto competencia percibida.

\section{Hallazgos}

\section{1. ¿Cómo se incorpora la computadora en las escuelas?}

Para analizar cómo se está trabajando con la computadora en las escuelas tomamos las respuestas de los alumnos al ítem: “¿Cuáles de las siguientes herramientas aprendes a usar en la escuela?" Siendo las opciones: 1) Procesadores de Texto (Word), Planillas de Cálculo (Excel), Presentaciones (Power Point), 2) Búsqueda por Internet, 3) Software para procesar imágenes y sonidos, 4) Lenguajes de Programación, 5) No usamos la computadora en la escuela, 6) otros.

En términos generales encontramos que en la mayoría de las escuelas los alumnos encuestados reportan utilizar herramientas que permiten aprender ofimática. En efecto, esta fue la frecuencia más amplia con un $84 \%$ del alumnado haciendo referencia en sus respuestas al uso de procesadores de textos, planillas de cálculos o herramientas para presentaciones en sus escuelas. Algunos también utilizan Paint y una escuela usa Autocad (software para diseño).

La segunda tarea más realizada en las escuelas fue la búsqueda por Internet seleccionada por el 63\% del alumnado en 11 de las 19 escuelas. El 38\% de los alumnos reportaron aprender a utilizar software para procesar sonidos e imágenes en 9 escuelas. Y un $49 \%$ de los alumnos de 9 escuelas seleccionan la opción de lenguajes de 
programación o bien expresan aprender computación en plataformas didácticas de pseudo lenguajes tales como Scratch, Micromundos, Alice, Logo, Etc.

Estos datos indicarían que en las escuelas relevadas predomina la incorporación de la computadora desde el paradigma del usuario puesto que aprender herramientas de ofimática y navegar por Internet fueron las principales actividades realizadas en las escuelas según reportan los alumnos.

\section{Usos de la computadora en escuelas públicas y privadas}

$\mathrm{Al}$ desagregar los datos entre escuelas privadas y públicas observamos que en las escuelas privadas hay un mayor uso de la computadora para todas las actividades mencionadas (un $10 \%$ a $20 \%$ más). Sin embargo, cuando comparamos el uso de herramientas de producción de tecnología y programación, la diferencia entre la cantidad de alumnos se duplica y triplica entre escuelas privadas y públicas. Es decir, a medida que se incorpora la computadora desde el paradigma lingüístico cultural orientado hacia la producción de tecnología se profundiza la diferencia entre escuelas privadas y públicas (Ver Gráfico 1).

Gráfico 1. Herramientas de computación utilizadas en las Escuelas privadas y públicas

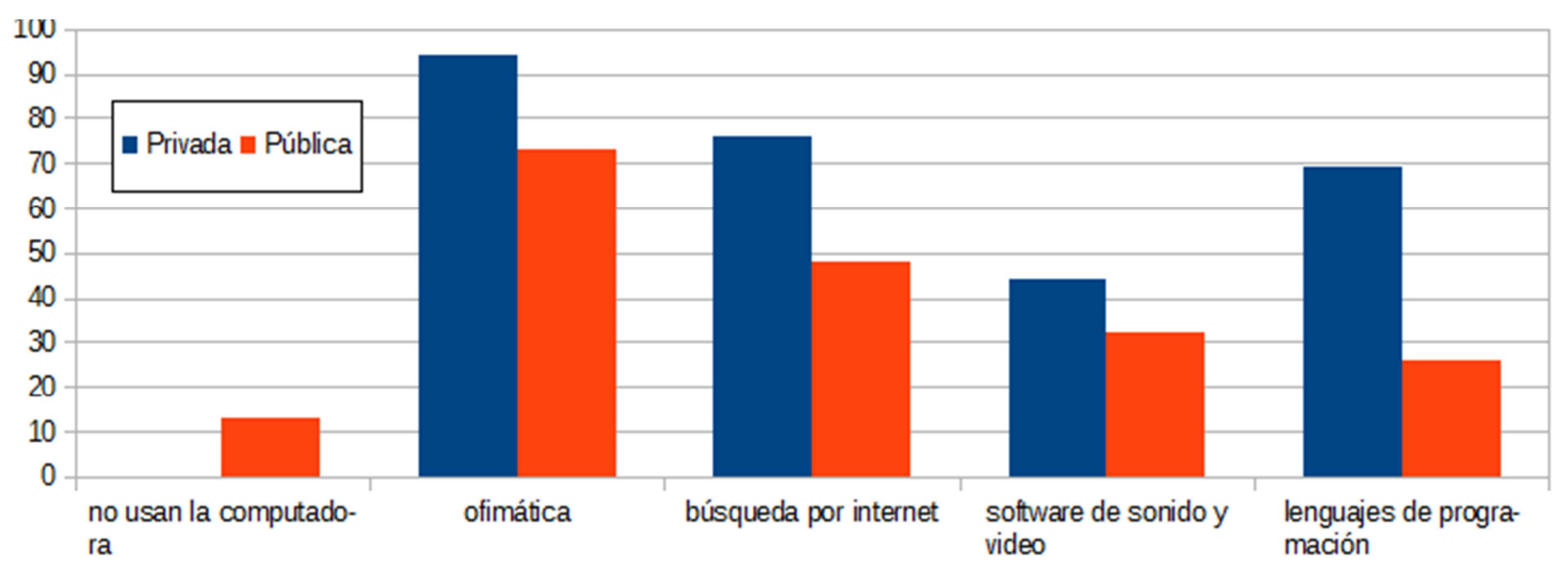

Según nuestros datos, 5 de las 14 escuelas públicas enseñan lenguajes de programación, contra 4 de las 5 escuelas privadas (Ver tabla 2). Para diferenciar entre escuelas donde sí se enseña programación y escuelas donde no se enseña programación, tomamos como referencia las respuestas de los alumnos. Aquellas escuelas donde el $35 \%$ de los alumnos o más reportó usar la computadora para aprender lenguajes de programación, fueron designadas como escuelas donde "sí" se enseña programación. Esto nos permitió incluir en esta categoría a escuelas que no tenían la orientación oficial, pero que habían incorporado la enseñanza de la programación a su curricula. Este dato no es menor ya que da cuenta de cómo algunas escuelas se van apropiando de esta innovación curricular a pesar de que todavía no está prescripta. De alguna manera estas escuelas están respondiendo con su oferta educativa a las demandas del ámbito social, educativo, industrial y científico. 
Tabla 2: Número de escuelas que enseñan diferentes herramientas de computación según tipo de gestión

\begin{tabular}{|l|l|l|}
\hline $\begin{array}{l}\text { Gestión/ Contenidos que aprenden } \\
\text { en la escuela }\end{array}$ & $\begin{array}{l}\text { Pública } \\
\text { escuelas) }\end{array} \quad(\mathrm{N}=14$ & Privada (N=5 escuelas) \\
\hline no usan la computadora & 2 & 0 \\
\hline Ofimática & 12 & 5 \\
\hline búsqueda por internet & 11 & 5 \\
\hline software de sonido y video & 6 & 3 \\
\hline lenguajes de programación & 5 & 4 \\
\hline
\end{tabular}

En 3 de las 4 escuelas primarias los chicos reciben alguna enseñanza de la programación. Sólo en la escuela primaria privada la enseñanza de la programación es parte del currículum de manera sostenida hace 20 años con la herramienta Logo primero y Micromundos actualmente. En efecto, el 85\% de los niños de la escuela primaria privada reporta aprender lenguajes de programación contra el $60 \%$ y $28 \%$ de los niños de las escuelas primarias públicas.

Según los relatos que recuperamos de la rectora de la escuela primaria privada, que sus alumnos tengan incorporada la programación en sus aulas se debe a dos razones: 1) las docentes de informática de la primaria empezaron enseñando programación con Logo a fines de la década de los 80s y han sido ellas mismas quienes han defendido este enfoque a pesar de que durante los 90s la prescripción oficial y también la presión institucional, les demandaba introducir ofimática. Como resultado de este proceso la ofimática entró a esta escuela, sin embargo se mantuvo la hora semanal de computación y el dictado de programación con Logo y luego Micromundos. Una de las docentes se jubiló en 2014 y otra está pronta a jubilarse. 2) La escuela tiene una impronta pedagógica escolanovista $\mathrm{y}$ por ello tiene como objetivo formar el "pensamiento". Desde este lugar la escuela sostiene que es coherente la enseñanza de la programación que contribuye al desarrollo del pensamiento lógico.

El caso de la escuela primaria no es único. Hemos encontrado recurrencia en similares relatos de docentes y ex alumnos de diferentes escuelas de la provincia que participaron de nuestros cursos de capacitación. Los adultos, al recordar una clase de computación de su infancia, coinciden en identificar el aprendizaje de programación a través de Logo o Basic si su paso por la escuela fue durante la década de los 80s. Aquellos más jóvenes, que atravesaron su escolaridad en los 90 s recuerdan en cambio experiencias de aprendizaje de ofimática.

En las otras dos escuelas primarias, la enseñanza de la programación en computación es parte de un proyecto piloto producto de un convenio entre el Ministerio de Educación de la Provincia de Córdoba y la firma Samsung para enseñar a programar a través de la plataforma Scratch. El Gobierno de Córdoba invitó a las docentes que 
realizan esta experiencia piloto a sumarse a nuestro programa en la Universidad. Esta experiencia es muy significativa en términos de la gesta de una política educativa que da cuenta de una respuesta concreta del gobierno provincial a la demanda de los diferentes sectores.

Usos de la computadora entre escuelas secundarias que tienen y no tienen orientación formal en programación

La diferencia entre el tipo de contenidos del área que ofrecen las escuelas es mayor entre escuelas privadas y públicas que entre escuelas que tienen orientación formal en computación y escuelas que no la tienen -solo escuelas secundarias se tomaron para esta comparación- (Ver gráfico 2). La diferencia entre la cantidad de alumnos que mencionaron utilizar herramientas para aprender programación entre escuelas con orientación formal en computación y escuelas sin orientación formal en computación es el doble. Esta misma comparación se triplica en cambio cuando se contrastan escuelas privadas y públicas.

Hemos podido también identificar que dos escuelas que formalmente tienen orientación en programación o informática ${ }^{\top}$ en todo el trayecto secundario, enseñan ofimática y el uso de procesadores de imágenes y sonido hasta cuarto año del secundario y sólo en quinto y sexto año enseñan programación.

Gráfico 2: Herramientas de computación utilizadas en las Escuelas con orientación y sin orientación formal en computación

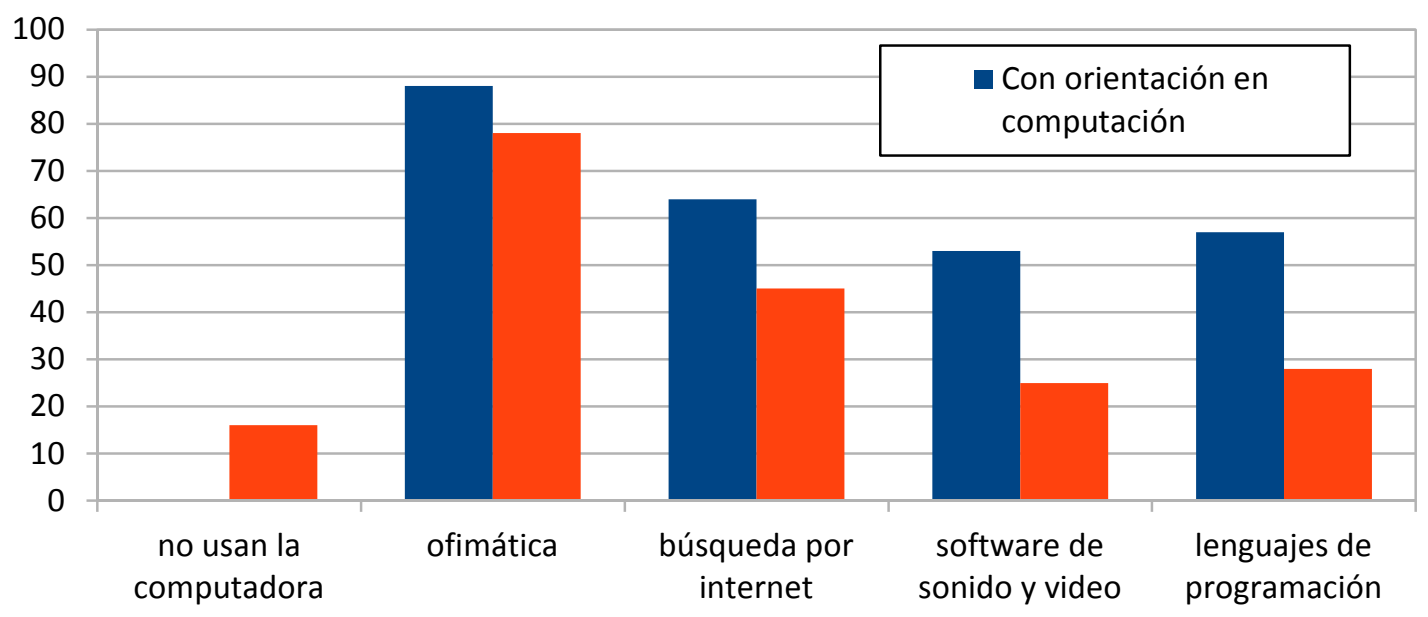

Un mayor porcentaje de alumnos de las escuelas secundarias con orientación en informática reportan aprender contenidos de lenguajes de programación con respecto a los alumnos que asisten a escuelas sin orientación en informática. El doble de alumnos de las escuelas con orientación reporta aprender lenguajes de programación (57\% vs $28 \%$ ) y software de video o sonidos (53\% vs $25 \%$ ). En cambio solo un $20 \%$ más de los

7 Estas denominaciones son las utilizadas oficialmente. 
alumnos de las escuelas con orientación manifiesta aprender a realizar búsquedas en Internet (64\% vs 45\%). Y un $10 \%$ más de los alumnos de las escuelas con orientación reporta aprender a utilizar herramientas de ofimática (88\% vs $78 \%$ ). Es decir, mientras más se alejan los contenidos de computación al paradigma de la formación del usuario y más se acercan al paradigma lingüístico, más se agudiza la diferencia entre las escuelas con orientación y sin orientación formal en CC. No observamos en esta muestra de escuelas una diferencia entre escuelas primarias y secundarias puesto que 3 de las 4 escuelas primarias que trabajaron con nosotros -recordemos que fueron autoseleccionadas- enseñan tanto programas de ofimática como de video, sonido y lenguajes de programación.

Estos datos concuerdan con las observaciones y relatos de docentes que recuperamos en nuestras experiencias de formación docente. Las escuelas con orientación formal en informática no estarían enseñando conceptos de computación principalmente, sino que incorporan a la enseñanza el uso de software de ofimática y producción digital (sonido e imágenes). Nos animamos a elaborar tres hipótesis complementarias que permitirían explicar este fenómeno. La primera hipótesis es que los docentes no estarían enseñando programación porque no tendrían la formación disciplinar adecuada. A menudo observamos que profesores con muy diversa formación ocupan los mismos cargos docentes. Generalmente los docentes de las materias relacionadas con la programación tienen formación como analistas de sistemas. Sin embargo, no sucede lo mismo con los docentes que enseñan materias que incluyen la denominación informática, tecnología o TIC.

La segunda hipótesis es que el paradigma desde el cual se apoyaría la enseñanza de la programación -el lingüístico cultural- estaría compitiendo con el paradigma dominante actualmente en las escuelas caracterizado por la integración de las TIC, o el uso de TIC de manera integrada. Advertimos que los docentes de computación se encuentran en un campo de tensión donde por un lado el currículum prescripto incluye contenidos de programación y las ciencias de la computación, pero por otro los cursos de capacitación docente que se ofrecen y los discursos de directores y especialistas promueven la integración de las TIC y el uso de la computadora transversalmente. Los docentes de programación e informática deben conciliar entonces en su práctica de enseñanza estas dos vertientes sobre cómo y para qué incluir la computadora en la escuela.

Una tercer hipótesis que hemos logrado construir con análisis más sistemático de encuestas a docentes se relaciona con la percepción social de que la programación en computación es "sólo para algunos" e "inaccesible a la gran mayoría de los jóvenes de secundario" (Ver Martínez y Echeveste, 2014). Gran parte de los docentes que asisten a nuestros cursos de capacitación menciona que opta por enseñar ofimática porque "es algo más útil" que la programación. En nuestras encuestas la mayoría de los docentes hace menciones a que los contenidos de las CC y programación son inaccesibles o muy difíciles para sus alumnos.

Representaciones de estudiantes de primaria y secundaria sobre las Ciencias de la Computación y su oficio. M. Cecilia Martínez y M. Emilia Echeveste.

Página 18 de 38 
Estas tres hipótesis permitirían explicar por qué los docentes de computación en escuelas que tienen la orientación formal en informática o programación decidirían no abordar profundamente contenidos específicos de la disciplina. Esta situación contribuiría a conformar representaciones en los jóvenes sobre las $\mathrm{CC}$ y la programación como uso de software y no como producción de tecnología.

Estos datos nos permiten plantear como hipótesis una brecha en el tipo de oferta educativa para el área de computación entre las escuelas públicas y privadas, principalmente donde los alumnos de las escuelas privadas tendrían en mayor medida acceso a saberes de computación relacionados con la formación en lenguajes y pensamiento computacional. La brecha entre las escuelas con orientación y sin orientación era esperada y deseable, sin embargo no es tan profunda como entre las escuelas públicas y escuelas las privadas.

Uno de los objetivos en esta investigación fue analizar qué representaciones y sentidos construyen los jóvenes, niños y niñas sobre las $\mathrm{CC}$ según el tipo de saberes de la disciplina que transmite la escuela. En la subsección que sigue analizamos esta cuestión.

\section{Representaciones sobre el oficio y la disciplina}

Una variable fundamental relacionada a la elección de cualquier carrera o trabajo tiene que ver con el conocimiento del oficio y de la disciplina. Los alumnos en general saben que los médicos curan, los músicos generan melodías, los actores participan en obras de teatro o películas, y podríamos seguir la lista. Sin embargo, es escaso el conocimiento que se tiene sobre lo que hace un especialista en computación. Para recuperar qué saben los alumnos del oficio del especialista en computación y sus representaciones sobre la disciplina, realizamos las preguntas abiertas "¿Qué hace un especialista en computación?" y "¿Qué es programar?”. A partir de la lectura de las respuestas, identificamos categorías que construimos inductivamente consistente con el enfoque exploratorio.

\section{Representaciones sobre el oficio: “qué hace un especialista en Computación”.}

En general advertimos que 7 de cada 10 alumnos tienen representaciones del oficio de la computación ligadas al paradigma utilitario, en tanto "uso" de programas elaborados por otros. En efecto, los alumnos mencionan que los especialistas en computación arreglan computadoras (38\%), instalan programas (16\%), navegan por Internet (3\%), o utilizan software disponible para diferentes tareas (generalmente mencionan los software de oficina) (14\%).

En contraste, 4 de cada 10 alumnos ofrecen una mirada del oficio del especialista de la computación más cercana al paradigma lingüístico donde los lenguajes son usados para producir tecnología. Los alumnos incluidos en este conteo se refirieron a que los especialistas en computación pueden crear programas (23\%), y más 
específicamente programar (19\%).

La suma de las proporciones señaladas supera el $100 \%$ puesto que se trataba de una respuesta abierta donde los alumnos escribían más de una opinión y todas fueron contabilizadas. La presencia de más de una idea sobre el oficio de la computación nos habla también de una convivencia de representaciones en donde el oficio de un especialista en computación sería visto entre los dos paradigmas el utilitario y el linguiístico.

Analizando inductivamente las respuestas abiertas de los alumnos emergieron 6 categorías que describen las representaciones que tienen los alumnos sobre el oficio del especialista en computación.

1) La categoría "arreglan computadoras" fue construida cuando los alumnos escribía respuestas tales como "arregla la computadora": "conecta la computadora", "saca los virus y esas cosas", "repara computadoras" y similares.

2) La categoría "Instalan programas" fue generada a partir de relatos tales como "baja" programas: "descarga" programas, "pone" juegos; "descargar programas de alguna buena manera", y similares.

3) Del mismo modo a partir de respuestas tales como "navega por Internet" "busca información en Internet", "Busca información importante" se construyó el emergente "navega por Internet".

4) El emergente "utiliza software" incluye a todas las menciones en que los jóvenes, niños y niñas hacen referencia a operar un software de oficina, generalmente comercial. Por ejemplo los chicos respondieron "escribir leyendas, usar Word", "usar todos los programas", "usar las aplicaciones", "usar programas nuevos" y similares.

5) Cuando los relatos de los chicos hacían referencia a producir a través de programar fueron codificados bajo las categorías "crear" sí así lo mencionaban (tales como crear juegos, crear programas).

6) La categoría "programar" reúne las respuestas relativas a "escribir programas", "escribir códigos", "programar". Si bien entendemos que para muchos las categorías "crear programas" y "programar" pueden ser equivalentes; consideramos que los jóvenes pueden referirse a dos situaciones cognitivas diferentes. La denominación "crear" está más ligada a lo expresivo, mientras que "programar" puede ser un acto menos expresivo y más mecánico. El gráfico 3 muestra los porcentajes de respuestas en cada categoría en el pre y post encuesta.

Luego asociamos las categorías arregla, instala, utiliza y navega al paradigma utilitario y las categorías crea y programa al paradigma lingüístico cultural.

Gráfico 3: Porcentaje de respuestas en pre y post encuesta ítem: ¿Qué hace un especialista en computación? 


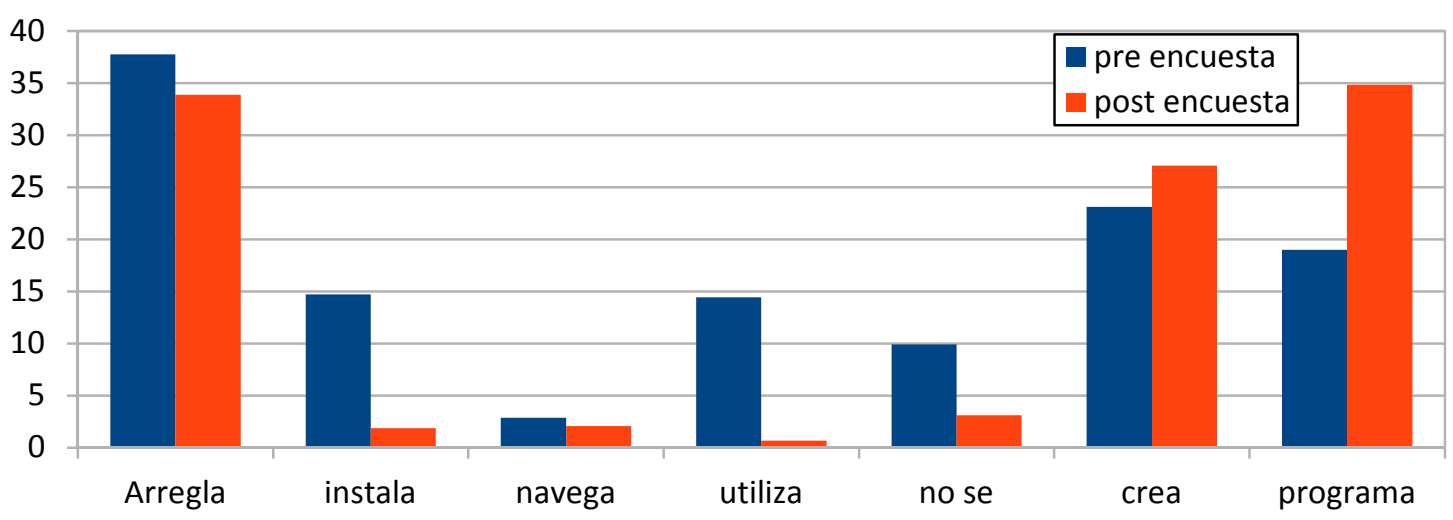

Como era esperado, se encontraron variaciones entre las respuestas de la pre y post encuesta realizadas luego de la intervención. Las respuestas que hacían referencia a "instalar programas", "utilizar los programas" y "no sé" decrecieron casi un $90 \%$ en la post encuesta al tiempo que las referencias a "crear programas" y "programar" aumentaron significativamente después de las 13 horas de clases de programación que les ofrecieron sus docentes. Teniendo en cuenta que la programación es un área central de la disciplina $\mathrm{CC}$ y es en dónde gira el debate actual sobre su posible introducción en la currícula obligatoria es que quisimos conocer cuáles eran las representaciones de los jóvenes en torno a esa actividad.

La fuerte impronta que tiene la representación de "arreglar computadoras" nos muestra que si bien han aumentado las respuestas orientadas al paradigma lingüístico no han podido desprenderse de la idea de un especialista en computación como alguien similar a un técnico. Se puede observar en las respuestas de las post encuestas cómo los estudiantes consideran las dos variantes. Citamos algunos ejemplos de respuestas a continuación: Un especialista en computación es aquel que "sabe hacer programas y arreglar computadoras", “Arregla computadoras y programa etc.”. "Lo que hacen es arreglar los problemas de las computadoras, hacen trabajos y hacen programas". Es "un administrador, analista, especialista de redes, depende de la aérea en que se destaca o estudio"; se encarga del "mantenimiento de Pc y la creación de software"; "programar, saber armar y desarmar computadoras, limpia computadoras". Hemos encontrado un predominio de este tipo de respuestas en las escuelas que cuentan con la orientación formal en computación.

\section{Representaciones sobre el oficio de programar}

El 50\% de los alumnos ligaron la tarea de programar con labores propias del paradigma técnico y utilitario describiendo la programación como mantenimiento de la computadora (19\%), instalación de programas (20\%), uso de la computadora para que funcione $(8 \%)$ y ordenar datos para que funcione (2\%). Solo el $29 \%$ de los alumnos se refirieron en la pre encuesta a la programación como acciones relacionadas al paradigma lingüístico tales como a dar órdenes (mencionado por 15\%), usar lenguajes 
(dicho por 5\%) y crear programar (sugerido por un 9\%). Mientras que un $22 \%$ mencionó que no sabía qué era programar o bien ofrecía respuestas que nos llevaron a pensar que desconocían de qué se trataba el trabajo de programar (por ejemplo una respuesta fue: "te sirve para la vida"). El gráfico 4 muestra el porcentaje de respuestas obtenidas a la pregunta "qué es programar" en pre y post encuesta.

Gráfico 4: Pre y post respuestas a ¿Qué es programar?

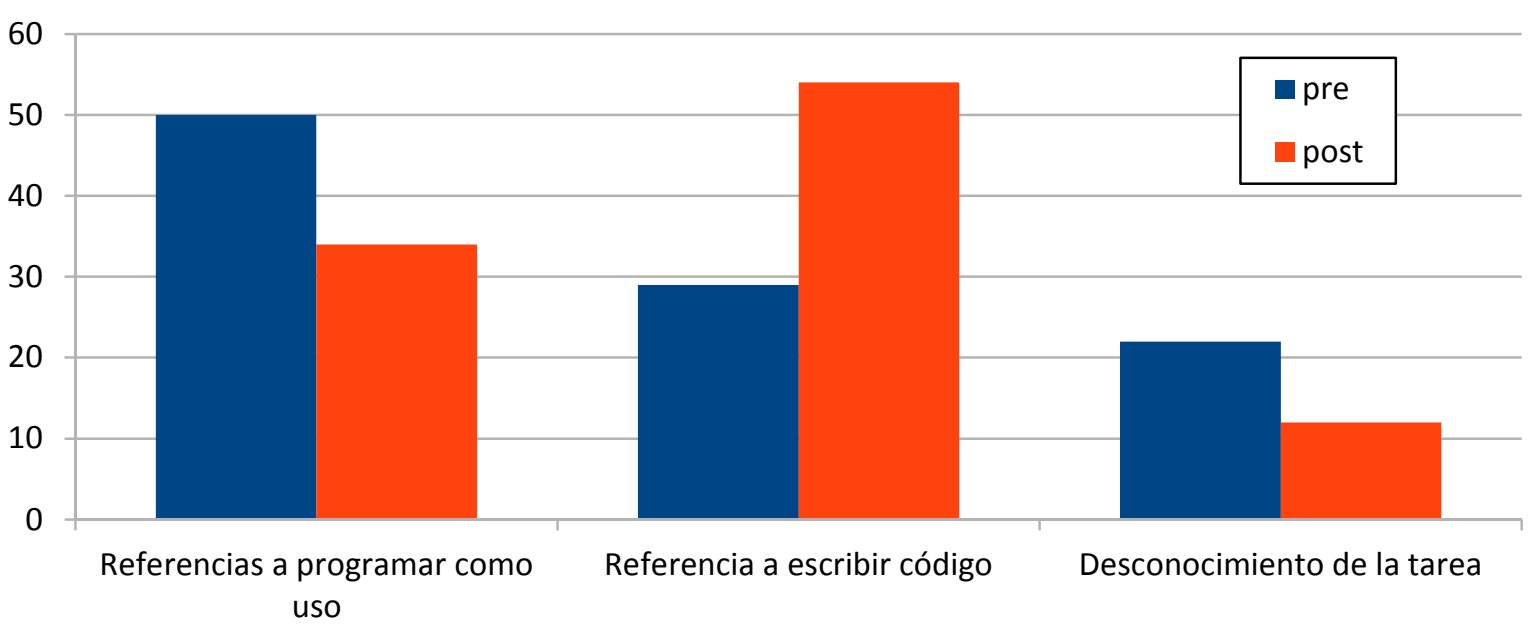

Este gráfico nos permite ver que nociones combinadas relativas a la programación como uso de la computadora bajaron después de la corta intervención de 13 horas de un $50 \%$ inicial a un $34 \%$. Lo contrario sucedió con los comentarios relacionados al paradigma lingüístico donde subieron de un $29 \%$ a un $54 \%$. Los comentarios sobre desconocimiento de la tarea también bajaron de un $22 \%$ a un $12 \%$.

Queremos profundizar los hallazgos en el incremento de las respuestas orientadas al paradigma lingüístico, ya que encontramos tres emergentes que sufrieron gran variación en la pre y post encuesta.

1) el emergente "programar es dar órdenes" se ha incrementado el doble en las respuestas apareciendo de manera específica. Por ejemplo los alumnos mencionaron: [programar] "es ponerle todo lo que uno quiere que tenga contenido, eso hace que la computadora funcione y reciba órdenes y pueda cumplirlas"; "ponerle acciones, códigos, ordenes, ponerle un objetivo". O bien pueden aparecer relacionadas a situaciones de la vida cotidiana, sobre toda en respuestas de alumnos de escuelas primarias: "programar es darle las ordenes a la compu como las mamás dicen que hacer" "es que te haga caso".

2) "Ordenar datos y que funcione" es el segundo emergente que ha aumentado un triple en las respuestas. Esto se pudo ver en respuestas como "significa ordenar los datos importantes y acomodar todos los programas, los documentos, las fotos entre otros"; "es poder establecer, tener una lista de acciones, poder hacer que se muevan las cosas, etc.". "Programar una computadora es clasificar, ingresar, organizar los datos, contenidos". 
3) Por último, el emergente "crear programas" presentó un incremento del doble de respuestas a la hora de contestar qué es programar, en los registros se observaron respuestas como "crear programas, editar programaciones y diseñar juegos, paginas, etc."; "hacer un software 0110100100101100001101001" (en referencia a que una computadora usa código binario); "son varios lenguajes para distintos programas para hacer subprogramas"; "crear algoritmos nuevos, mejorar los programas ya hechos, e investigar qué otras cosas se pueden desarrollar, etc." Muchas de las respuestas de los alumnos de primaria estaban relacionadas a actividades de videojuegos o actividades propias de la plataforma que usamos para la intervención, como ser "programar es darle vida a los objetos"; "hacer juegos y videos" "para mi programar una computadora es programar un "elemento". En estos casos deducimos que efectivamente el trabajo en las clases de 13 hs contribuyó a formar una noción de programación.

\section{Diferencias entre las escuelas públicas y privadas}

Al desagregar los datos por tipo de gestión de escuela (privada y pública), nivel educativo (primario y secundario) y oferta de enseñanza de computación (escuelas que sí enseñan programación según lo reportaron más del 35\% de sus alumnos), observamos que la diferencia de las respuestas para el ítem "qué hace un especialista en computación" entre la pre y post encuesta es más profunda cuando comparamos escuelas públicas y privadas, donde por ejemplo las referencias al trabajo de "arreglar" una computadora se modifican poco en las escuelas de gestión pública y casi 8 puntos en las escuelas de gestión privada. Las nociones referidas a "programar" aumentan en mayor medida en la privada contra la pública. El Gráfico 5 muestra la diferencia de respuestas por tipo de gestión. Asimismo, adjuntamos en el Anexo 2 las tablas comparativas de la pre y post encuestas por tipo de orientación y por nivel educativo.

Además, las respuestas relativas a la programación aumentan especialmente cuando miramos solamente el nivel primario. En efecto, solo un $8 \%$ de los estudiantes de primaria mencionó en la pre encuesta que un especialista en computación "programaba" contra un $35 \%$ mencionado en la post encuesta.

Sin embargo, cuando preguntamos sobre el trabajo específico de la programación mediante el ítem "qué es programar" observamos que hay una mayor diferencia en el cambio de creencias sobre la programación en las escuelas públicas (Ver gráfico 6).

Gráfico 5. Comparación de respuestas sobre el ítem qué hace un especialista en computación por tipo de gestión 


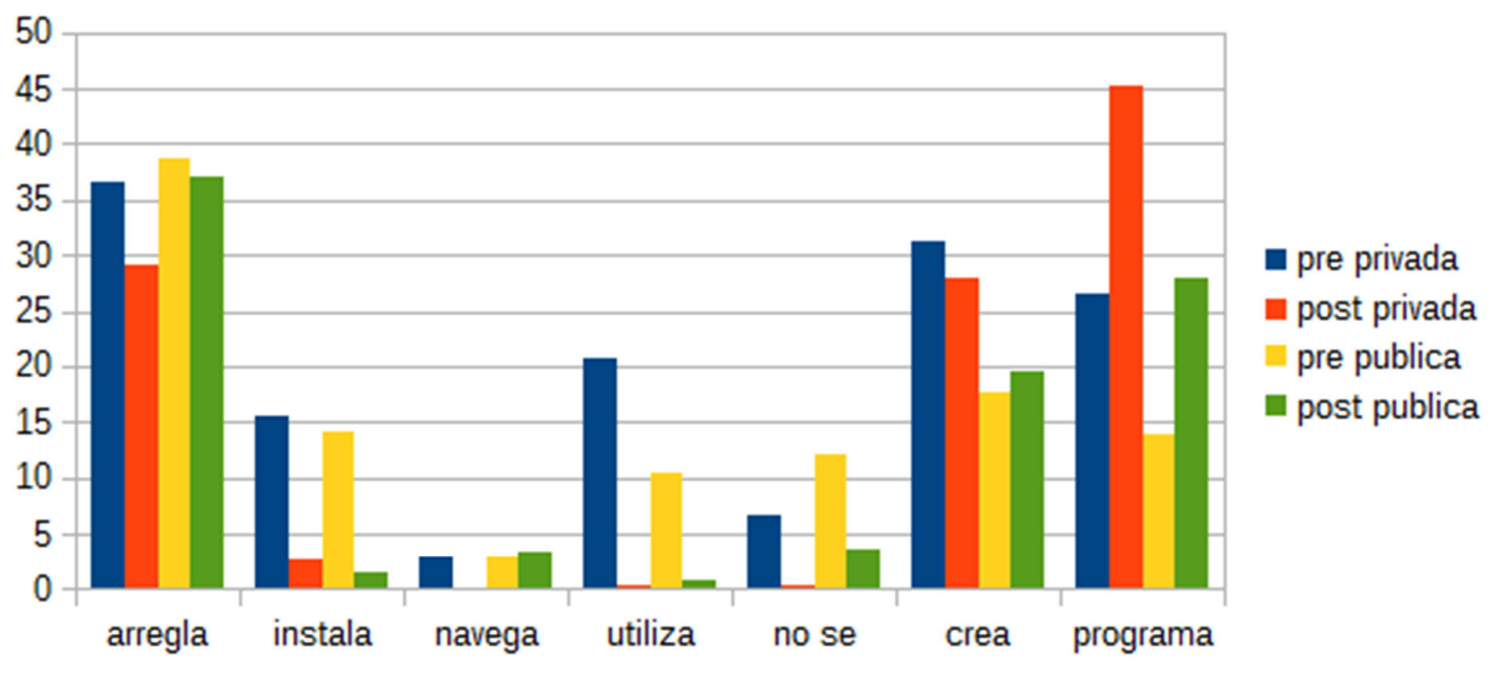

Gráfico 6: Respuestas sobre qué es programar por tipo de gestión

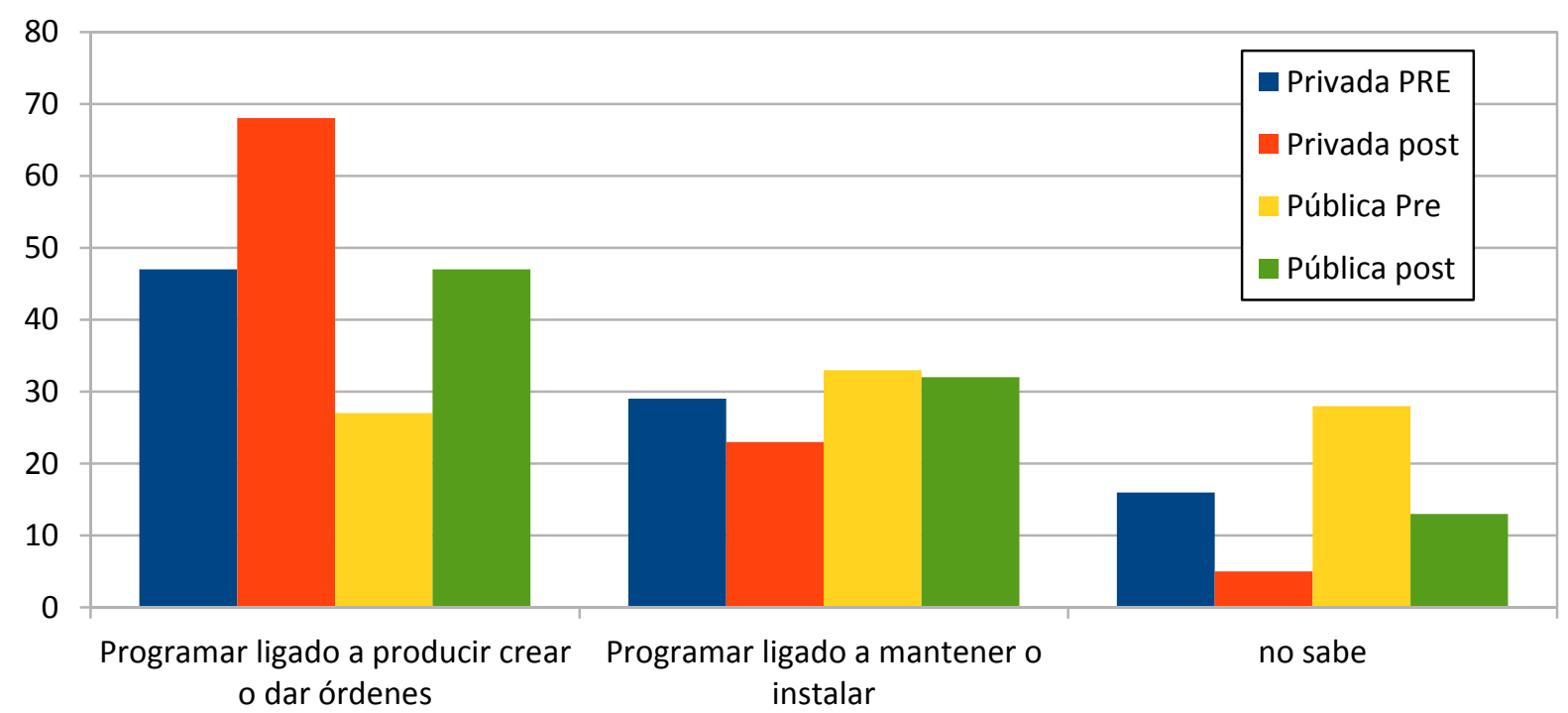

Esto podría deberse a que antes de tomar nuestro curso de programación de 13 horas casi $30 \%$ de los alumnos de las escuelas públicas reportó no saber qué era programar y un $32 \%$ mencionó que programar era mantener la computadora, instalar programas, enseñar computación u ordenar datos. Es decir, el punto de partida respecto a nociones sobre la programación en las escuelas públicas se distanciaba mucho del contenidos aprendidos en nuestro curso o dicho de otra manera, el contenido sobre programación era totalmente novedosos para ellos y por eso el cambio de representaciones sobre la tarea de programar fue mayor que en la privada donde ya había algunas nociones previas.

Este hallazgo está íntimamente ligado con la sección anterior donde mostramos que las escuelas privadas estarían enseñando contenidos más cercanos a la programación. En efecto, 47\% de los alumnos de las escuelas privadas hicieron referencias en la pre encuesta a que programar era crear programas, escribir lenguajes, o dar órdenes contra $27 \%$ de las públicas. 
Así mismo observamos que, si bien, después de la experiencia de intervención, los alumnos de la escuela públicas muestran un cambio profundo en favor de considerar la programación ligada a programar y crear, se observa una dificultad para desprenderse del paradigma utilitario.

Diferencias entre las escuelas que enseñan programación y que no enseñan programación

Al comparar los datos pre y post encuesta desagregados entre escuelas que sí enseñan programación (tal como como lo indicaron más del $35 \%$ de sus alumnos), con escuelas donde no se enseña programación, vemos también que el mayor cambio de representaciones respecto a qué hace un especialista en computación ocurre entre las escuelas donde no se enseñaba programación. El gráfico 7 permite ver las diferentes respuestas.

Gráfico 7: comparación entre escuelas que sí enseñan programación y escuelas que no enseña programación sobre qué hace un especialista en computación.

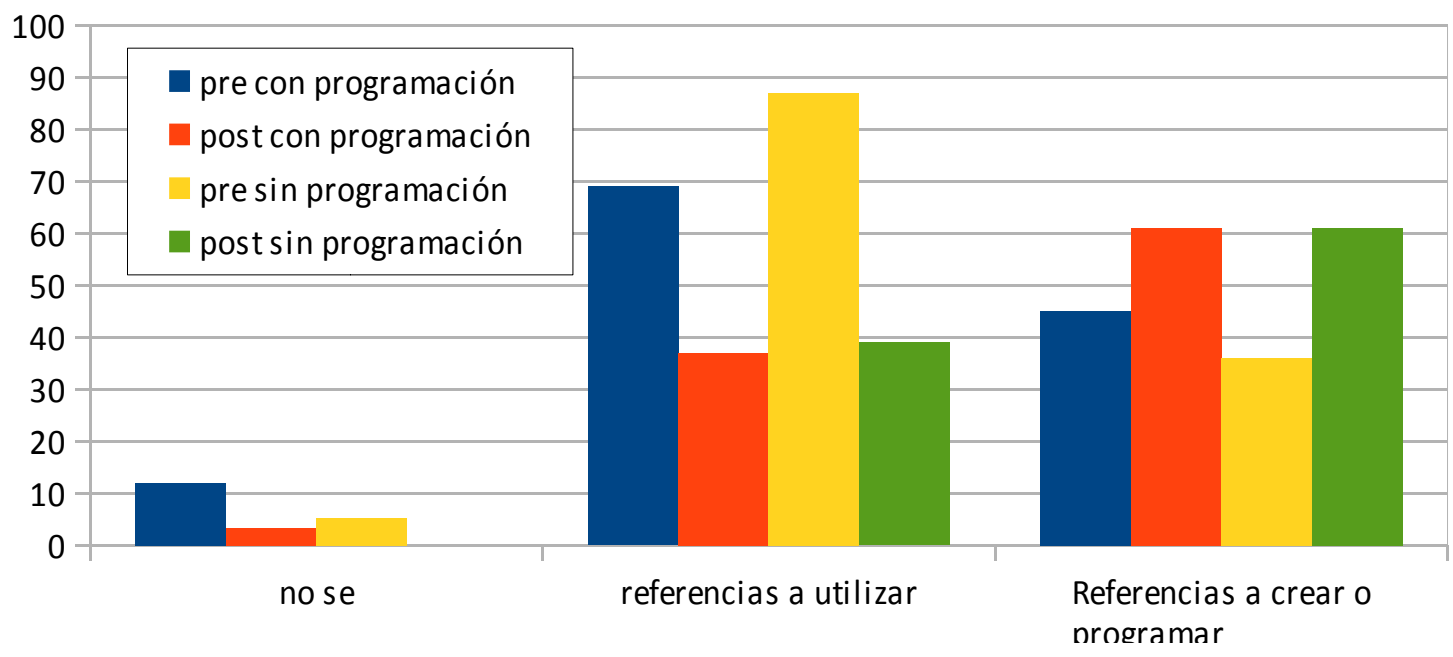

En la pre encuesta al ítem “¿qué hace un especialista en computación?” el 87\% de los alumnos de las escuelas donde no se enseña programación hicieron referencia a que un especialista en computación "utiliza programas elaborados por otros" (tales como programas de oficina, Internet o arregla la computadora) mientras que solo un $1,75 \%$ del mismo grupo lo menciona en la post encuesta. Asimismo, solo el 36\% de los alumnos de las escuelas que no enseñan lenguajes de programación mencionaron que un especialista en computación "programa" o "crea" programas, mientras que lo hicieron un $45 \%$ de los alumnos de las escuelas con programación. Durante la post encuesta ambos grupos de alumnos aumentaron sus referencias a que un especialista en computación programa, pero el aumento fue relativamente mayor en las escuelas donde no se abordaba la programación pasando de $36 \%$ a $61 \%$ mientras que los alumnos de las escuelas donde sí enseñaba programación pasaron de un $45 \%$ a un $61 \%$. 
Podemos decir que la acotada intervención de 13 horas de clases de programación contribuyó a que la mayoría los alumnos cambiarán sus creencias sobre la actividad que realiza un especialista en computación, produciendo un cambio de pensamiento que va desde un paradigma más utilitario de la computación al más lingüístico. Del mismo modo, pondríamos como hipótesis, y en razón de los datos obtenidos, que la enseñanza de computación desde el enfoque del paradigma "utilitario" estaría generando representaciones ligadas a la computación como herramienta y no como disciplina que permite producir tecnología.

Respecto a las concepciones sobre qué es programar observamos que el $45 \%$ de los estudiantes de escuelas donde sí se enseña programación, según lo reportaron más del 35\% de los alumnos de esa escuela, relacionan a la programación con dar órdenes, escribir código, ordenar datos, usar lenguajes, crear programas o crear videojuegos. En cambio, un $47 \%$ de los alumnos de las escuelas donde no se enseña programación sostienen que programar es instalar software, usar computadoras, o configurar software (Gráfico 8)

Según nuestros datos, los alumnos que más se beneficiarían con el curso de 13 horas serían los alumnos de las escuelas donde ya se enseñaba programación. Pensamos que efectivamente el conocimiento y competencias previas que los alumnos ya tenían o venían construyendo en sus escuelas les permitieron apropiarse más profundamente del sentido de la programación con el curso de 13 horas y que quizás un curso tan corto sería insuficiente para cambiar sustancialmente las creencias entorno a la disciplina.

Gráfico 8: Respuestas a qué es programar entre escuelas que enseñanza y no enseñan

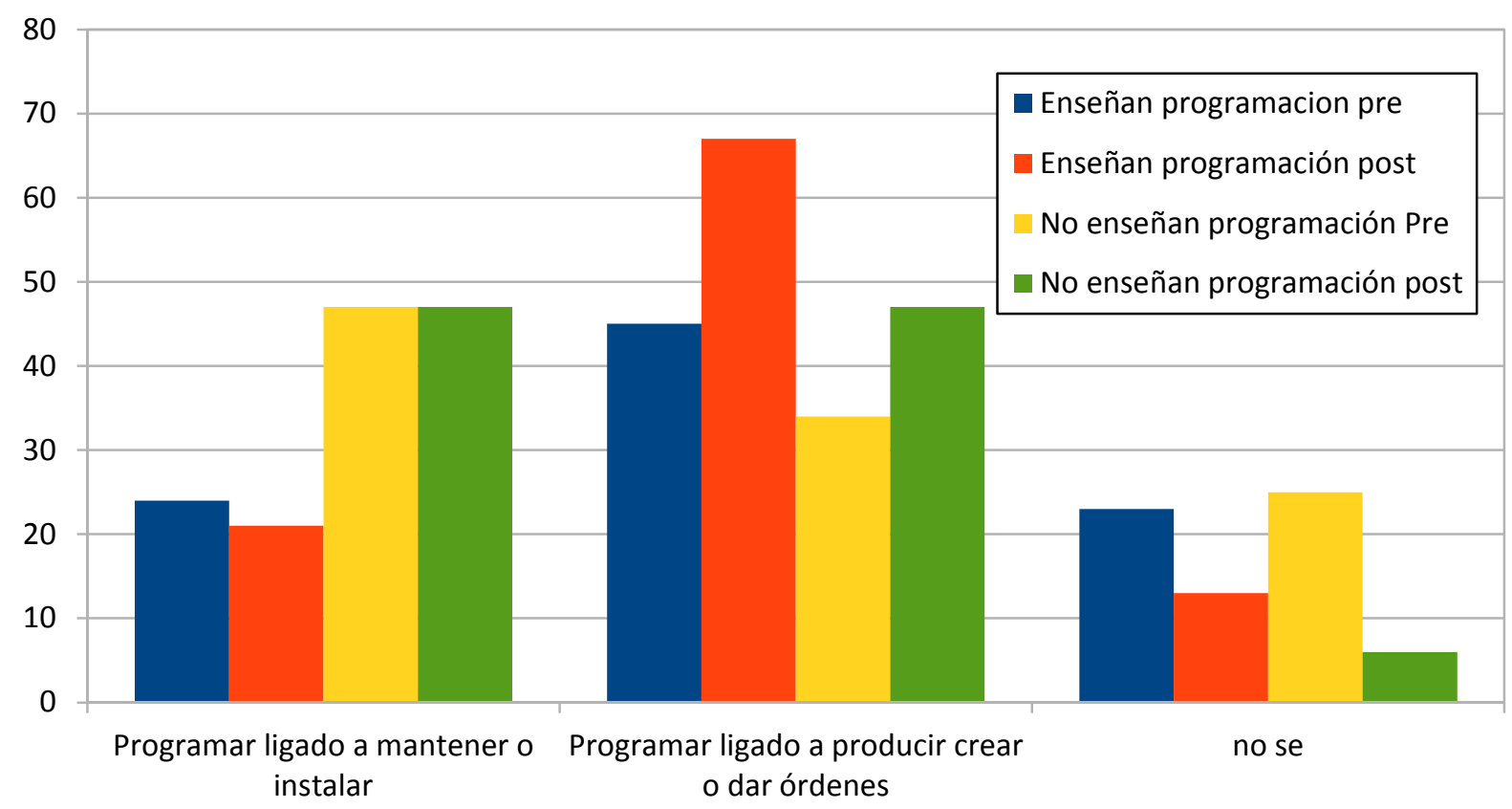

Representaciones de estudiantes de primaria y secundaria sobre las Ciencias de la Computación y su oficio. M. Cecilia Martínez y M. Emilia Echeveste. 


\section{Autopercepción de competencia}

Además del acceso temprano a la disciplina y las representaciones sobre el oficio que conlleva cada disciplina, la autopercepción de competencia, en tanto la mirada que los jóvenes tienen sobre sus propias capacidades, es una variable crucial para la selección de las carreras de computación.

Nuestros datos muestran que a partir de esta experiencia el curso de 13 horas no ha cambiado la cantidad de las respuesta por la positiva a la pregunta "piensas que podrías crear programas nuevos" tomada como indicador de auto competencia, tal como se ve en la tabla.

Tabla 3: Piensa que podrías crear programas nuevos, pre y post respuestas.

\begin{tabular}{|l|l|l|}
\hline Respuesta & Pre & Post \\
\hline Si & $73 \%$ & $74 \%$ \\
\hline No Sé & $4 \%$ & $0 \%$ \\
\hline NO & $23 \%$ & $25 \%$ \\
\hline
\end{tabular}

Sin embargo, para el $74 \%$ de todos los alumnos aprender a programar les resultó fácil o muy fácil; para el $68 \%$ aprender a programar fue interesante o muy interesante y al $62 \%$ del estudiantado le gustaría aprender a programar con Alice.

Este interés que reportan los alumnos lo pudimos ver en las observaciones de clases donde los estudiantes se mostraban muy entusiasmado con el curso y ha sido documentado en otro trabajo (Benotti, Martinez, Schapachnik, 2013).

Lo que nos resultó más interesante fue analizar inductivamente las respuestas a la pregunta abierta "por qué sí o por qué no piensas que podrías crear nuevos programas". Encontramos que las razones para crear nuevos programas o no son las mismas y elaboramos 4 categorías a partir de los relatos de los niños y jóvenes.

1) Percepción de competencia (positiva o negativa). Incluimos en esta categoría a referencias que hacían los alumnos a sus capacidades para crear un programa tales como: "porque puedo aprender a hacerlo", "porque estamos aprendiendo a hacerlo", "porque tengo imaginación", "soy creativo", "puedo hacerlo con ayuda", etc. Para percepción negativa de competencia encontramos que los alumnos hacían referencia a que no son pacientes, no son buenos para esa tarea, la programación es complicada y difícil. También incluimos aquí referencias al conocimiento de la disciplina cuando los alumnos manifestaban tener un dominio de la disciplina o no en el caso de la negativa. Por ejemplo: "porque yo sé computación", "porque ya lo hice". Y en el caso de la negativa: porque no sé computación, porque no entiendo, porque lo que sé no es suficiente para programar.

2) Gusto: En esta categoría incluimos las referencias a que programar "es interesante", "emocionante", "me gusta jugar". Y por la negativa cuando decían cosas como: "es aburrido", "no me interesa", "no me gusta la computación". 
3) Utilidad: este emergente sólo lo encontramos en las respuestas por la positiva donde los alumnos hacían referencia a que querían crear programas porque sería útil, pueden ayudar a otras personas que lo necesitan y pueden trabajar de eso.

4) Sin respuesta. Aquí incluimos respuesta en blanco como referencias tautológicas ej: "porque no quiero", "porque no".

En la lectura de nuestros datos encontramos que no cambiaron las posiciones iniciales los que pensaban que no podrían crear programas se sostuvieron- pero sí han variado sus las razones. Notamos que la categoría percepción de competencia, es la que mayor variación tuvo entre la pre y la post encuesta tal como muestra el gráfico 9.

Gráfico 9: Razones por las cuales los alumnos piensan que podrían crear programas

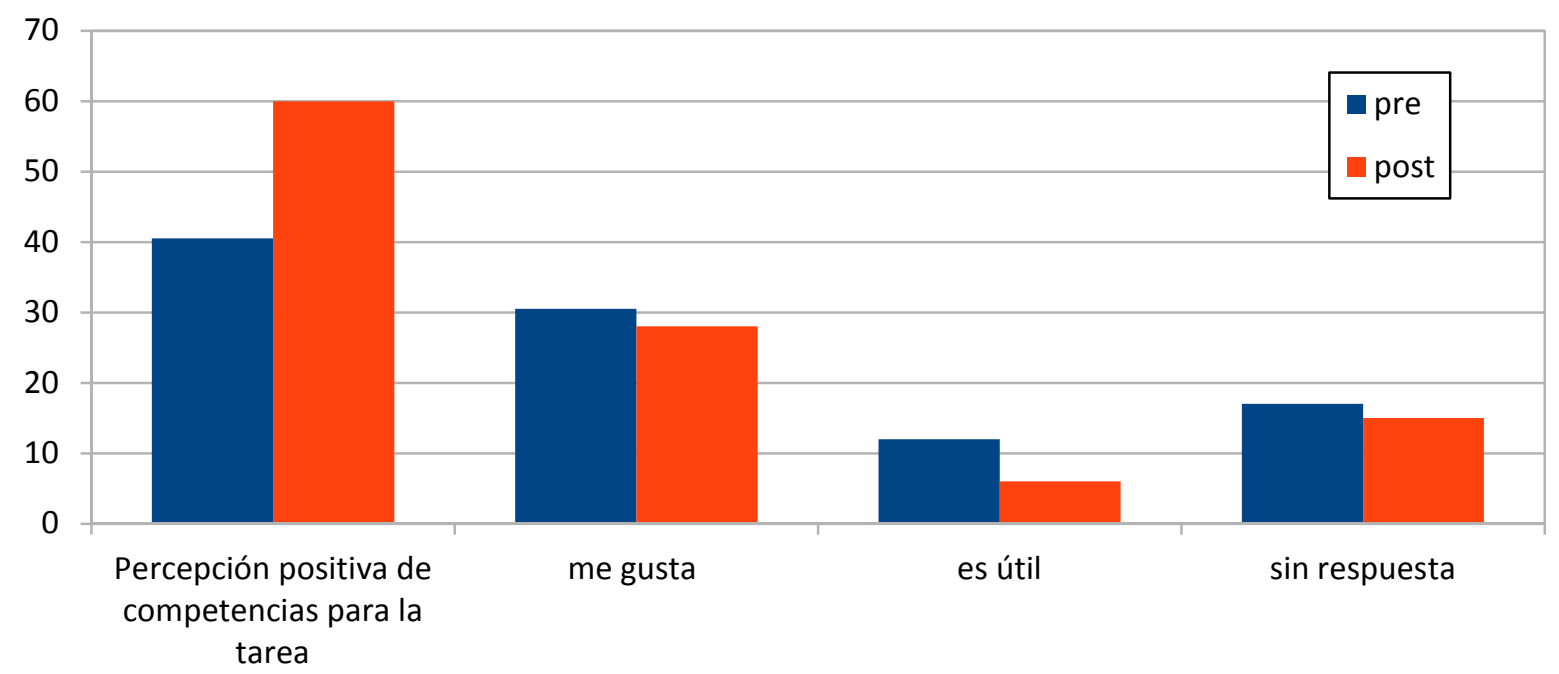

Gráfico 10: Razones por las cuales lo alumnos piensan que no podrían crear programas

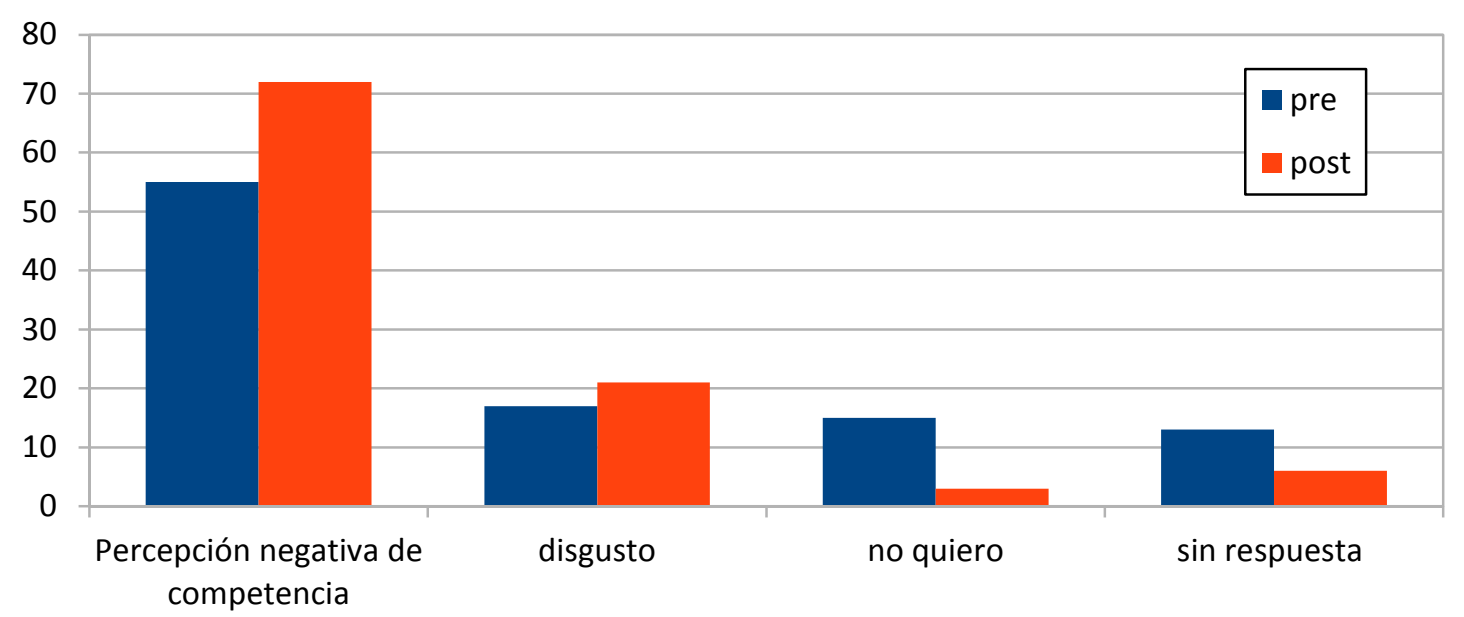

Observamos en estos gráficos que las principales razones que los alumnos atribuyen a su posibilidad de crear programas de computación están relacionadas con su 
percepción de competencia y que el curso de 13 horas parecería profundizar estas creencias que los alumnos construyen de sus competencias.

Consideramos que este resultado se relaciona con el tipo de experiencia de aprendizaje que estuvo a disposición de los alumnos., basada fundamentalmente en la construcción de un producto tecnológico. El aprendizaje basado en proyectos activa la exploración y descubrimiento de conceptos que permiten analizar y elaborar el proyecto. Para poder elaborar un proyecto es necesario desarrollar competencias y no solamente memorizar o repetir conceptos. Sostenemos que debido a que los estudiantes pudieron ver de manera concreta que ellos mismos podían lograr un producto tecnológico con la programación, construyeron una percepción positiva de sus capacidades. Las razones por las que se piensa que no pueden crear programas pensamos que tiene relación simétrica atribuyendo sus razones a no tener las competencias.

\section{Conclusiones e Implicancias para la Política Educativa}

A partir de analizar los datos presentados en este trabajo podemos establecer tres conclusiones generales y sus respectivas implicancias para las políticas educativas.

1) Todas las escuelas independientemente del nivel educativo, la gestión y la orientación incorporan la computadora a sus escuelas desde un enfoque predominantemente utilitario ofreciendo para los alumnos herramientas de computación que sólo permiten desarrollar habilidades operativas.

Quizás, muchas de ellas integran la computación para potenciar otras disciplinas. Nuestros datos lamentablemente no nos permiten ver este proceso en particular, pero lo que sí podemos observar es que son pocas las escuelas que estarían enseñando conceptos de computación relacionados con el pensamiento computacional y la programación.

No pretendemos hacer generalizaciones sobre este hallazgo, no era el objetivo de este trabajo, más aún donde la muestra fue de escuelas autoseleccionadas donde había un interés previo en enseñar computación. Pero sí es importante observar que aún en escuelas con interés previo y en escuelas que tienen la orientación formal de programación, el enfoque predominante es el utilitario.

Este hallazgo nos preocupa y nos inquieta. Nos preocupa porque el uso intenso de la computadora que pueden estar haciendo los alumnos en las escuelas puede dar la falsa ilusión de que se está enseñando computación, cuando en realidad se están desarrollando en los alumnos habilidades de operarios de programas que desconocen cómo y por qué funcionan. De la misma manera nos preocuparía que se enseñe a usar la calculadora en nombre de la matemática o mecanografía en nombre de la escritura.

Nos inquieta porque a pesar de los esfuerzos de incorporar tecnología específica educativa, aún para promover el paradigma integrador, la mayoría de las escuelas siguen utilizando herramientas de ofimática. Asimismo, existen al menos una decena de 
herramientas que permitiría aprender programación y desarrollar el pensamiento computacional, pero las escuelas no las están considerando.

Un programa de introducción de las Ciencias de la computación en la escuela deberá formar a los docentes en los conceptos centrales de la disciplina y ofrecer herramientas específicas para enseñarla.

2) Las escuelas privadas en mayor medida estarían ofreciendo experiencias de enseñanza de la programación y pensamiento computacional. Este dato indica que en vez de cerrar las brechas digitales, ante el vacío legal, prescriptivo, y formativo en la enseñanza de la computación; las escuelas privadas van incorporando a su cartera saberes relevantes y actualizados para sus alumnos, profundizando las brechas sociales ya existentes.

En este punto el rol del estado es ineludible, porque desde la conformación de las sociedades modernas republicanas, el aparato público es garante del derecho educativo. Esto es que todos los estudiantes del nivel obligatorio reciban una educación de calidad y relevante para nuestro momento histórico.

La deserción de estudiantes de nivel secundario es altísima en toda Latinoamerica, y paradójicamente es el nivel educativo que más ha crecido incorporando a sectores que por primera vez en la historia de nuestros países serán primera generación de graduados de nivel secundario ${ }^{8}$. Sin embargo, los estudiantes que están incluidos en el sistema educativo no logran concluir sus estudios o acuerdan en que "no aprenden". Sabemos que el desafío es la calidad, pero calidad también requiere incorporar saberes relevantes para nuestro momento histórico, que carguen de sentido la experiencia de aprendizaje de nuestros alumnos. Que a partir de los saberes que la escuela ofrece, los alumnos puedan entender y pensar en intervenir el mundo que nos rodea para solucionar los problemas que a ellos mismos los ocupan. En este momento histórico mediado altamente por la tecnología en todas las áreas del conocimiento, esta premisa es casi imposible sin tener conceptos centrales de computación.

En este punto, sostenemos que el rol del Estado, en tanto garante de derecho educativo, es ineludible. Formalizar la enseñanza de las Ciencias de la Computación es sólo un primer paso hasta que esto ocurra en las escuelas, pero es el primer paso que el Estado debe dar en este momento.

3) Encontramos una relación entre la oferta de enseñanza y las representaciones sobre el oficio y la disciplina que construyen los alumnos. Aquellos alumnos que reciben una oferta educativa en donde la computación ingresa para aprender a programar, tienen una visión diferente del trabajo y el saber de las Ciencias de la Computación. Estas representaciones son las principales variables que orientan la selección de carreras relacionadas con la computación.

\footnotetext{
${ }^{8}$ Para el caso de la provincia de Córdoba se calcula que el $80 \%$ de los estudiantes de secundario de escuelas públicas serían primera generación de egresados secundarios en su familia.
} 
Nuevamente, enseñar Ciencias de la Computación en la escuela, en tanto pensamiento computacional, permitiría a los alumnos construir diferentes representaciones de la disciplina más cercanas a los tipos de trabajos y conocimientos que tienen los especialistas en computación.

En todos los contextos donde enseñamos nuestro curso los alumnos cambiaron sus representaciones. Es decir, que la introducción a la programación sería accesible tanto para primaria, secundaria, pública, privada, escuelas con y sin orientación en computación. No es necesario tener características previas para incorporar la enseñanza de la computación en cuanto al nivel educativo o tipo de escuela. Sin duda, las escuelas que más se beneficiaron, donde las pre y las post encuestas mostraron mayores diferencias, fueron aquellas escuelas donde previamente no se enseñaba programación.

Si tenemos en cuenta el punto de vista del enfoque costo-beneficio propio del análisis de políticas públicas, este hallazgo podría ser un indicador de que las escuelas públicas, donde mostramos que existe la mayor brecha de tipo de oferta de enseñanza, tendrían un mayor beneficio al mismo costo.

Quisiéramos destacar que el enfoque pedagógico con el cuál se abordó la enseñanza de la programación fue orientado por el aprendizaje por descubrimiento, ofreciendo a los alumnos múltiples oportunidades para acercarse al modo de trabajo de los especialistas en computación y a los conceptos centrales de la disciplina. Pensamos que otro enfoque de enseñanza, más cercano a la repetición de algoritmos por ejemplo, no hubiera tenido los mismos resultados. Nuestra hipótesis es que la enseñanza de la computación es significativa, cuando el enfoque con el cual se aborde permite apropiaciones profundas de los conceptos y desarrollar habilidades de alto orden propias de la disciplina tales como el pensamiento computacional.

Este trabajo no cierra nuestra indagación, sino que nos deja pensando nuevas preguntas: qué rol tuvieron los docentes, por qué la percepción de auto competencia se profundiza tanto para la negativa como para la positiva, qué relación habría entre auto competencia y representaciones, son estadísticamente significativas las varianzas, etc. Un trabajo exploratorio como este generalmente aporta pocas certezas y abre nuevas preguntas que abordaremos en los próximos meses.

Presentación del manuscrito: 28 de agosto de 2015

Fecha de aprobación: 5 de septiembre de 2015

Fecha de publicación: 15 de septiembre de 2015

Martínez, C. y Echeveste, M.E. (2015). Representaciones de estudiantes de primaria y secundaria sobre las Ciencias de la Computación y su oficio. RED. Revista de Educación a Distancia,46(13). 15 de Septiembre de 2015. Consultado el (dd/mm/aa) en http://www.um.es/ead/red/46 


\section{Bibliografía}

Bell, T. (2014). Establishing a nationwide CS curriculum in New Zealand high schools. Communications of the Association for Computing Machinery, 57, 28-30.

Bell, T., Andreae, P., \& Lambert, L. (2010). Computer science in New Zealand high schools. In Proceedings of the Twelfth Australasian Conference on Computing Education - Volume 103 (pp. 15-22).

Benitez Larghi, S. et al. (2013). De Brechas, pobrezas y apropiaciones. Juventudes, Sectores Populares y TIC en la Argentina. Versión. Estudios de Comunicación y Política. Diponible en http://version.xoc.uam.mx/index.php?option=com_content \&view=article \&id=77\%3 Ade-brechas-pobrezas-y-apropiaciones \&catid=35\%3Aversion-tematica\&Itemid=44. Acceso 04/03//2013.

Benítez Larghi, S. et al. (2010) "La apropiación de las TIC por jóvenes de sectores populares urbanos en espacios de acceso público" En Revista Argentina de Estudios de Juventud. Número 3. Diciembre 2010. Facultad de Periodismo y Comunicación Social. Universidad Nacional de La Plata.

Benitez Larghi, S y otros (2013) TIC, clase social y género. La Constitución de desigualdades sociales y digitales en las juventudes argentinas. X Jornadas de Sociología. Facultad de Ciencias Sociales, Universidad de Buenos Aires, Buenos Aires, 2013.

Benotti, L; Martinez, M. C; Schapachnick, F; (2014) Engaging High School Students Using Chatbots. En Tony Clear; Arnold Pears (Eds) Proceedings Of The 2014 Conference On Innovation \& Technology In Computer Science Education. New York, Ny.: Acm (American Computer Machinery). P63 - 69. Isbn 978-1-4503-28333

Bouille, J. (2008): "Cibercafés o la nueva esquina. Usos y apropiaciones de internet en jóvenes de sectores populares urbanos", en: Urresti, M: Ciberculturas juveniles. Los jóvenes, sus prácticas y representaciones en la era de Internet. Buenos Aires: La crujía.

Bourdieu, P. (1991). El Sentido práctico. España: Taurus Humanidades.

Bourdieu, P. (1979). La distinción. Criterios y bases sociales del gusto. España: Taurus.

Busaniche, Beatriz (2006) "Alfabetización digital: las fronteras del aprendizaje y el control de la Información". Disponible en http://www.bea.org.ar/wpcontent/uploads/2006/10/alfabetizaciondigital.html

Camacho, K. (2005). La brecha digital. En AMBROSI, A., PEUGEOT, V., y PIMIENTA, D. Palabras en juego: Enfoques Multiculturales sobre las Sociedades de la Información. París: C \& F Éditions.

Castoriadis, C.(1997). El Imaginario Social Instituyente.Zona Erógena. № 35. 
Castorina y Barreiro (2006) Las representaciones sociales y su horizonte ideológico. Una relación problemática. Boletín de Psicología, $N$ 86. Marzo

Cuthill, M. (2002). Exploratory research: citizen participation, local government and sustainable development in Australia. Sustainable Development, 10(2), 79.

Creswell, John W. Research design: Qualitative, quantitative, and mixed methods approaches. Sage publications, 2013.

Furber, S. (2012). Shut down or restart? The way forward for computing in UK schools. Technical Report The Royal Society, London.

ESDL (European Computing Driver Licence Foundation). (2015) La Falacia del Nativo Digital. Informe Técnico.

Fundación Sadosky (2013) CC-2016. Una propuesta para refundar las enseñanza de la computación de las escuelas Argentinas. Buenos Aires.

Levis, D (2007) Enseñar y aprender con informática/ enseñar y aprender informática. Medios informáticos en la escuela argentina. Buenos Aires: Prometeo.

Maldonado M. (2000) Una escuela dentro de una escuela. Un enfoque antropológico. sobre los estudiantes secundarios en una escuela pública de los 90. Buenos Aires: Editorial Eudeba.

Manaris, B. (2007). Dropping CS enrollments: or the emperor's new clothes? ACM SIGCSE Bulletin, 39(4), 6-10.

Morales, S., \& Loyo. (2005). La orfandad de los nativos digitales. In 1 er Encuentro sobre Juventud. Medios de Comunicación e Industrias Culturales. Retrieved from http://www.perio.unlp.edu.ar/observatoriodejovenes/sites/perio.unlp.edu.ar.observa toriodejovenes/files/morales.pdf

Martinez, M.C y Echeveste, M. E (2014). El rol de las comunidades de aprendizaje en la construcción de una visión común para la enseñanza de computación en las escuelas. Revista Iberoamericana de Investigación Educativa. (65)

Martinez, M. C.; Gomez, M; Benotti, L.(2015). A Comparison Of Preschool And Elementary School Children Learning Computer Science Concepts Through A Multilanguage Robot Programming Platform. En Carsten Schulte; Tatjana Jevsikova (eds) Proceedings Of The 2015 Conference On Innovation \& Technology In Computer Science Education. New York: Acm (American Computer Machinery). P - . Isbn 9781450328333

Ortega, F. (2008) Atajos. Saberes escolares y estrategias de evasión. Buenos Aires: Ed. Miño y Dávila. 
Scott, C., et al. (2009). More than a bumper sticker: The factors influencing information systems career choices. Communications of the Association for Information Systems, 24(1), 2.

Shackelford, R., et al. (2006, March). Computing curricula 2005: The overview report. In ACM SIGCSE Bulletin (Vol. 38, No. 1, pp. 456-457). ACM. Disponible en http://www.acm.org/education/curric_vols/CC2005-March06Final.pdf

Tenti Fanfani, E. La escuela y la cuestión social. Ensayos de sociología de la educación. Buenos Aires: Siglo XIX..

Tiramonti, G (2013) "Claves para mirar las políticas educativas de la región" en Baez Sus M y García J M: "Aportes para (re)pensar el vínculo entre Educación y TIC en la región". Uruguay.

Urresti, M. (2008) Ciberculturas juveniles. Los jóvenes, sus prácticas y representaciones en la era de Internet. Buenos Aires: La Crujía,.

Wing, J.M. (2006). Computational thinking. Communications of the ACM, 49(3), 3335 .

Zuckerfeld, M. et al. (2014) ¿Y las mujeres dónde están? Primer estudio de la Fundación Sadosky sobre la presencia femenina en Informática. Informe técnico. Fundación Sadosky.

Zur Bargury, I. (2012). A new curriculum for junior-high in computer science. In Proceedings of the 17th ACM Annual Conference on Innovation and Technology in Computer Science Education (pp. 204-208) 


\section{ANEXO I}

\section{Instrumento de recolección de datos. Variables e Indicadores de las Encuestas}

\begin{tabular}{|c|c|}
\hline Variables & $\begin{array}{l}\text { Indicadores (operacionalizados en preguntas a las } \\
\text { encuestas) }\end{array}$ \\
\hline Identificación & Apellido \\
\hline Identificación & Nombre \\
\hline \multicolumn{2}{|c|}{ ABAJO PREGUNTAS SOLAMENTE REALIZADAS EN LA PRE ENCUESTA } \\
\hline Edad & ¿Cuántos años tenés? \\
\hline Género & Género \\
\hline Socioeconómico & ¿Cómo se llama tu escuela? \\
\hline Nivel Educativo & $\begin{array}{l}\text { ¿Estás en primaria o secundaria? ¿En qué grado o año } \\
\text { estas? }\end{array}$ \\
\hline \multicolumn{2}{|c|}{$\begin{array}{l}\text { Usos de la computadora en la siguientes actividades en la computadora, tablet o } \\
\text { vida cotidiana } \\
\text { celular inteligente? (rango de opciones) }\end{array}$} \\
\hline \multicolumn{2}{|c|}{$\begin{array}{l}\text { ¿Tenés computadora, tablet o celular inteligente en tu } \\
\text { Acceso material a computación casa? }\end{array}$} \\
\hline \multicolumn{2}{|c|}{$\begin{array}{l}\text { Para vos ¿qué cosas hace un especialista en } \\
\text { Concepciones previas acerca } \\
\begin{array}{l}\text { computación? } \\
\text { del significado de la ¿Qué pensás que } \\
\text { programación }\end{array} \\
\text { computadora? (Abierta) }\end{array}$} \\
\hline \multicolumn{2}{|c|}{$\begin{array}{l}\text { ¿Cuáles de las siguientes herramientas aprendés a usar } \\
\text { en la escuela? (múltiple opción) Programas para } \\
\text { procesar sonido e imágenes/ Word y power point/ } \\
\text { Búsqueda por internet/ Lenguajes de programación } \\
\begin{array}{l}\text { Enseñanza de la computación (como Java, Micromundo, Scratch, etc)/ No usamos la } \\
\text { en la escuela } \\
\text { computadora en la escuela/ Excel/ Otro: }\end{array}\end{array}$} \\
\hline \multicolumn{2}{|c|}{ ABAJO PREGUNTAS REALIZADAS EN LA PRE Y POST ENCUESTA } \\
\hline Asociadas a 1 & ¿Pensás que podrías crear programas nuevos? \\
\hline
\end{tabular}




\begin{tabular}{|c|c|}
\hline $\begin{array}{l}\text { Autopercepción sobre } \\
\text { capacidad en computación }\end{array}$ & su Contanos por qué sí o por qué no. (Abierta) \\
\hline Interés en programación & $\begin{array}{l}\text { ¿Te gustaría crear programas nuevos? Contanos por } \\
\text { qué sí o por qué no. (Abierta) }\end{array}$ \\
\hline $\begin{array}{l}\text { Participación en clases } \\
\text { computación }\end{array}$ & $\begin{array}{l}\text { ¿Cuántas veces en cada clase de informática o } \\
\text { de tecnología hacés preguntas o comentarios (del tema) a } \\
\text { tu profe o compañeros? (Múltiple opción) }\end{array}$ \\
\hline $\begin{array}{l}\text { Conocimientos aprendidos } \\
\text { el curso }\end{array}$ & $\begin{array}{l}\text { ¿Qué conceptos o temas aprendiste de computación en } \\
\text { este curso? (Múltiple opción) objetos, recursión, ciclo } \\
\text { en o lazo, condicional o si/sino, inducción, número } \\
\text { aleatorio, variable, evento, otros. }\end{array}$ \\
\hline $\begin{array}{l}\text { Interés y motivación } \\
\text { aprender computación }\end{array}$ & $\begin{array}{l}\text { ¿Por cuál de estas razones aprenderías } \\
\text { computación?(Múltiple opción ) Porque quiero crear } \\
\text { mis propios programas/ Me va a servir en cualquier } \\
\text { en trabajo o profesión aunque no sea de computación/ } \\
\text { Otro: }\end{array}$ \\
\hline $\begin{array}{l}\text { Conocimiento de } \\
\text { computación en los artefac } \\
\text { de la vida cotidiana }\end{array}$ & $\begin{array}{l}\text { Cuáles de estos artefactos te parece que necesitan de } \\
\text { la programas de computadoras para funcionar? (múltiple } \\
\text { tos opción) Celular/ Tarjeta de Colectivo/ Auto } 0 \mathrm{~km} / \\
\text { Enchufe / Lámpara }\end{array}$ \\
\hline Elección de carrera & $\begin{array}{l}\text { ¿Qué te gustaría hacer cuando termines el secundario? } \\
\text { En el caso que elijas estudiar después de terminar el } \\
\text { secundario ¿qué carrera/s te gustaría seguir? ( Abierta) }\end{array}$ \\
\hline
\end{tabular}

\section{ABAJO PREGUNTAS SOLAMENTE REALIZADAS EN LA POST ENCUESTA}

Facilidad en Programación a En una escala de 0 a 10, cuán fácil te resultó aprender a través de Alice programar en Alice?

En una escala de 0 a 10: cuánto te interesó aprender a programar en Alice?

Interés de Programación a te gustaría aprender más a programar con Alice? través de Alice. te gustaría aprender a programar en otros lenguajes?

¿Cuáles fueron los mejores momentos de este curso? ¿Qué actividades (clases o eventos) hubieras hecho Valoración de actividades diferente en este curso? (Abierta) 
Anexo 2: Porcentaje de respuestas sobre qué hace un especialista en computación en las pre y post encuesta por escuelas.

Comparación entre escuelas de gestión pública y gestión privada

\begin{tabular}{|l|l|l|l|l|}
\hline & pre privada & post privada & pre publica & post publica \\
\hline arregla & $36,48 \%$ & $29,1 \%$ & $38,58 \%$ & $37 \%$ \\
\hline instala & $15,64 \%$ & $2,62 \%$ & $14,07 \%$ & $1,38 \%$ \\
\hline navega & $2,88 \%$ & $0,2 \%$ & $2,89 \%$ & $3,33 \%$ \\
\hline utiliza & $20,58 \%$ & $0,41 \%$ & $10,34 \%$ & $0,87 \%$ \\
\hline no se & $6,6 \%$ & $0,41 \%$ & $12,13 \%$ & $3,57 \%$ \\
\hline crea & $31,26 \%$ & $27,93 \%$ & $17,67 \%$ & $19,6 \%$ \\
\hline programa & $26,55 \%$ & $45,2 \%$ & $13,94 \%$ & $27,92 \%$ \\
\hline
\end{tabular}

Comparación entre escuelas que sí enseñan programación y escuelas que no enseñan programación

\begin{tabular}{|l|l|l|l|l|}
\hline & $\begin{array}{l}\text { pre con } \\
\text { computación }\end{array}$ & $\begin{array}{l}\text { contación } \\
\text { computa }\end{array}$ & $\begin{array}{l}\text { sin } \\
\text { computación } \\
\text { computación }\end{array}$ \\
\hline arregla & $40,54 \%$ & $33,31 \%$ & $31,33 \%$ & $34,14 \%$ \\
\hline instala & $14,93 \%$ & $1,5 \%$ & $14,77 \%$ & $2,77 \%$ \\
\hline navega & $2,21 \%$ & $2,9 \%$ & $4,46 \%$ & $0 \%$ \\
\hline utiliza & $11,16 \%$ & $0,23 \%$ & $22,07 \%$ & $1,75 \%$ \\
\hline no se & $11,92 \%$ & $3,29 \%$ & $5,2 \%$ & $0 \%$ \\
\hline crea & $20,6 \%$ & $21,4 \%$ & $28,8 \%$ & $37,01 \%$ \\
\hline programa & $24,25 \%$ & $39,62 \%$ & $6,69 \%$ & $23,61 \%$ \\
\hline
\end{tabular}

Comparación entre escuelas primarias y secundarias 


\begin{tabular}{|l|l|l|l|l|}
\hline NIVEL & pre primaria & post primaria & pre secundaria & post secundaria \\
\hline arregla & $28,63 \%$ & $31,14 \%$ & $41,65 \%$ & $35,45 \%$ \\
\hline instala & $15,38 \%$ & $0,83 \%$ & $14,33 \%$ & $2,43 \%$ \\
\hline navega & $6,65 \%$ & $0,27 \%$ & $1,28 \%$ & $2,85 \%$ \\
\hline utiliza & $17,81 \%$ & $2,3 \%$ & $12,99 \%$ & $0 \%$ \\
\hline no se & $9,03 \%$ & $0,55 \%$ & $10,28 \%$ & $3,03 \%$ \\
\hline crea & $12,1 \%$ & $6,42 \%$ & $27,82 \%$ & $30,01 \%$ \\
\hline programa & $8,36 \%$ & $34,68 \%$ & $23,54 \%$ & $34,89 \%$ \\
\hline
\end{tabular}

